Natural Hazards and Earth System Sciences, 5, 931-946, 2005

SRef-ID: 1684-9981/nhess/2005-5-931

European Geosciences Union

(C) 2005 Author(s). This work is licensed

under a Creative Commons License.

\title{
A magnetotelluric study of the sensitivity of an area to seismoelectric signals
}

\author{
G. Balasis ${ }^{1}$, P. A. Bedrosian ${ }^{1, *}$, and K. Eftaxias ${ }^{2}$ \\ ${ }^{1}$ GeoForschungsZentrum Potsdam, Telegrafenberg, 14473 Potsdam, Germany \\ ${ }^{2}$ Solid State Section, Physics Department, University of Athens, Panepistimiopolis, Zografos, 15784 Athens, Greece \\ *now at: US Geological Survey, Denver, Colorado, USA
}

Received: 21 July 2005 - Revised: 11 October 2005 - Accepted: 12 October 2005 - Published: 23 November 2005

Part of Special Issue "Seismic hazard evaluation, precursory phenomena and seismo electromagnetics"

\begin{abstract}
During recent years, efforts at better understanding the physical properties of precursory ultra-low frequency pre-seismic electric signals (SES) have been intensified. Experiments show that SES cannot be observed at all points of the Earth's surface but only at certain so-called sensitive sites. Moreover, a sensitive site is capable of collecting SES from only a restricted number of seismic areas (selectivity effect). Therefore the installation of a permanent station appropriate for SES collection should necessarily be preceded by a pilot study over a broad area and for a long duration. In short, a number of temporary stations are installed and, after the occurrence of several significant earthquakes (EQs) from a given seismic area, the most appropriate (if any) of these temporary stations, in the sense that they happen to collect SES, can be selected as permanent. Such a long experiment constitutes a serious disadvantage in identifying a site as SES sensitive. However, the SES sensitivity of a site should be related to the geoelectric structure of the area that hosts the site as well as the regional geoelectric structure between the station and the seismic focal area. Thus, knowledge of the local and regional geoelectric structure can dramatically reduce the time involved in identifying SES sites. In this paper the magnetotelluric method is used to investigate the conductivity structure of an area where a permanent SES station is in operation. Although general conclusions cannot be drawn, the area surrounding an SES site near Ioannina, Greece is characterized by: (1) major faults in the vicinity; (2) highly resistive structure flanked by abrupt conductivity contrasts associated with large-scale geologic contacts, and (3) local inhomogeneities in conductivity structure. The above results are consistent with the fact that electric field amplitudes from remotely-generated signals should be appreciably stronger at such sites when compared to neighboring sites.
\end{abstract}

Correspondence to: G. Balasis

(gbalasis@gfz-potsdam.de)

\section{Introduction}

The observation of pre-seismic electric signals (SES) revealed the so-called selectivity effect (e.g. Varotsos and Lazaridou, 1991; Varotsos et al., 1993, 1996), in which (i) SES are observed only at particular sites of the Earth's surface (sensitive sites) and (ii) each sensitive site can only record SES from certain focal areas (e.g. see Uyeda, 1996).

The concept of selectivity and its origin has widely been discussed by several authors: Lazarus (1993) requires the signal to propagate preferentially through regions of high dielectric constant (e.g. pure water), linking preferred epicenters and sensitive regions; Utada (1993) favors the existence of planar conductive electric field guides linking the earthquake epicenter with the observer; Hadjicontis and Mavromatou (1996) explain selectivity in terms of particular circuits between the source and the observer, involving conduction and displacement currents.

The following model for the explanation of the selectivity effect has been suggested (Varotsos and Alexopoulos, 1986; Varotsos et al., 1993): the earthquake (EQ) preparation zone lies in the vicinity of a fault, which may provide a conductive path whose conductivity, $\sigma_{p}$, is order(s) of magnitude larger than that of the surrounding medium, $\sigma_{\text {host }}$ (Ritter et al., 2005; Bedrosian et al., 2004). When the SES is emitted, electric current follows the most conductive channel, in this case a fault. Thus, if the emitting current dipole source (Varotsos et al., 1998) lies close to a highly conductive path (terminating below the Earth's surface) and the measuring station lies at a location close to the upper end of the conductive channel and preferably close to a high resistivity anomaly, the electric field measured is appreciably stronger than in the case of a homogeneous or horizontally layered Earth.

On the other hand, the aforementioned ideas and models on selectivity have been strongly contested (Kagan and 
Jackson, 1996; Pham et al., 1998) and it was also suggested that they are in many cases geologically unreasonable (Tzanis et al., 2000; Tzanis and Vallianatos, 2001). We frame this study as a means to test one of the main theories (i.e. a highly conductive path channel with upper end close to a resistive anomaly). The result does not imply that this mechanism is correct, but simply shows that it is consistent or inconsistent with the theory. This source model, i.e. a dipole source lying in the vicinity of a horizontal conductive pathway of limited depth extent, is of extremely simple geometry. In the real Earth, structure is often more complex (Sarlis et al., 1999) and the preferential current pathway may consist of a complicated sequence of indirectly connected (elongated) conductive bodies. The above model emphasizes the importance in determining the geoelectrical structure beneath (and around) possible candidate SES sites.

The magnetotelluric (MT) method is used for investigating the conductivity structure of the Earth's crust and upper mantle (Vozoff, 1987). Geomagnetic Depth Sounding (GDS) surveys provide an independent picture of the subsurface conductivity structure. Over a period of 4 years, MT and GDS measurements (period range 0.01-1000 s) were collected from 42 sites in an area of $30 \times 40 \mathrm{~km}^{2}$ in the Ioannina region of NW Greece (Balasis, 2001; Balasis et al., 2002; Eftaxias et al., 2002). In this area an SES station (PER) has been operating for almost 2 decades. The area of the field experiment, the location of the sites with respect to the nearby Ionian Sea and a close-up of the site array are given in Fig. 1a-c, respectively. As mentioned, the target of this survey was to understand the geoelectric conditions which characterize an area sensitive to the detection of electric signals from a current emitting, embedded, dipole source. Galvanic and magnetic distortion analysis techniques were applied to the full dataset in order to define dimensionality and strike. The estimated electromagnetic (EM) induction transfer functions from a subset of the sites were then inverted using a 2-D inversion algorithm along a SW-NE oriented, $35 \mathrm{~km}$ profile crossing the Ioannina area, and a resistivity model was obtained for the area under investigation.

\section{Galvanic distortion analysis of the Ioannina MT impedance estimates}

In the magnetotelluric method the relationship between the horizontal components of the EM field is expressed through a pair of linear equations,

$E_{x}=Z_{x x} H_{x}+Z_{x y} H_{y}$

$E_{y}=Z_{y x} H_{x}+Z_{y y} H_{y}$.

In matrix notation this condenses to:

$$
\mathbf{E}=\stackrel{\leftrightarrow}{\mathbf{Z}} \mathbf{H}
$$

where $\overleftrightarrow{\mathbf{Z}}$ is the MT impedance tensor. The magnetotelluric technique is based on the study of the impedance tensor, i.e. the stationary transfer function relating the horizontal components of the magnetic to the corresponding components of the electric or telluric field.

Special symmetries of Earth conductivity structure (i.e. $\sigma=\sigma(z)$ or $\sigma=\sigma(y, z))$ lead to special forms of the impedance tensor, i.e. to the one-dimensional (1-D) or twodimensional (2-D) case, respectively. In the 2-D case, with no structural variation in the x-direction, Maxwell's equations decouple into two modes. The first is the TE mode (transverse electric) and describes the field components $E_{x}$, $H_{y}$ and $H_{z}$ observed when the electric currents are flowing along (parallel to) structural boundaries. The second is the TM mode (transverse magnetic) and relates the field components $H_{x}, E_{y}$ and $E_{z}$ when currents are crossing (perpendicular to) structural boundaries. The axis along which resistivity does not vary (the $\mathrm{x}$-axis in this example) is the axis of uniformity, or strike direction. The variation of $\overleftrightarrow{\mathbf{Z}}$ with respect to rotation $\theta$ detects vertical conductivity boundaries, whereas its variation with frequency $\omega$, due to the skin-depth effect, is sensitive to horizontal boundaries. From the elements of the impedance tensor we obtain the following scalar quantities: the apparent resistivity, $\varrho_{a, i j}$, and the phase of the impedance, $\phi_{i j}$, where $(i, j=x, y)$. Finally, appropriate inversion schemes are applied to the apparent resistivities and phases to derive Earth conductivity models.

One of the most challenging problems in magnetotellurics is the effects that local near-surface conductivity inhomogeneities have on the MT impedance estimates. The presence of these anomalies can produce effects that in turn can seriously modify the measured impedance tensor (Jones, 1983; Park, 1985). It is therefore necessary to understand the static distortions in determinining the appropriate strike angle, i.e. determining the coordinate frame into which to rotate the data for subsequent 2-D modeling.

Advances are being made in understanding the effects that near-surface inhomogeneities have on MT responses. To address this problem approximate parameterization techniques have been developed which deal with local features as if their EM fields are at the galvanic (DC) limit. The only observable effect in the data due to such inhomogeneities is the result of electric charges bound to the surfaces of them.

The effect of distortion on the electric field is frequencyindependent, causing amplitude shifts and rotation of the MT impedances (Ritter, 1996). In its simplest form, for data from either 1-D or 2-D (rotated into the strike direction) Earth models, this problem manifests itself as a shift of the apparent resistivities by a frequency-independent multiplicative constant without affecting the phases, and is termed a static shift (Jones, 1988).

In its more general form, static distortions have been addressed by modeling the effects of three-dimensional (3D) galvanic bodies within a 2-D regional Earth. A number of methods have been developed to recover the 2-D strike direction in such a case, and to decompose the observed MT tensor into component tensors that separately describe the distortions and the regional 2-D conductivity 
(a)
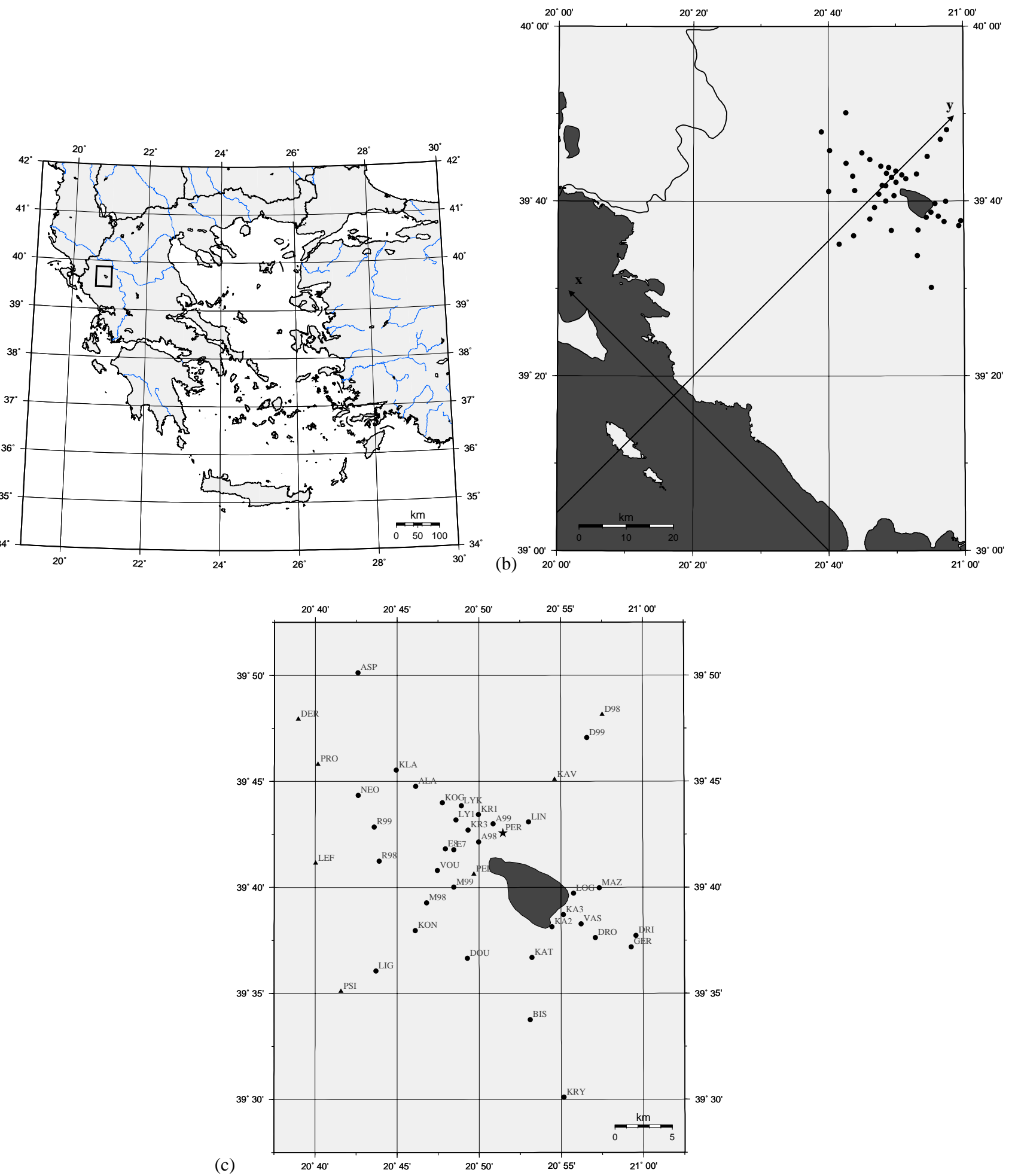

Fig. 1. Map of Greece where the area of the measurements (rectangle) is indicated (a). Location of the sites in relation to the nearby coastline (b). Map with names of the sites; the SES station (PER) is denoted by a star; the Ioannina lake is also indicated (c). (In (c) triangles denote stations in which Mohr circles of the impedance tensors, as we see later, do not pass through the origin.)

distribution (Bahr, 1988; Groom and Bailey, 1989). The Groom-Bailey decomposition gives the parameters required (principal impedances, strike angle, twist and shear) as well as the confidence with which to believe the estimates, and their approach is used routinely by many researchers in order to derive appropriate strike angle and distortion parameters (Wei et al., 2001; Ritter et al., 2003). 

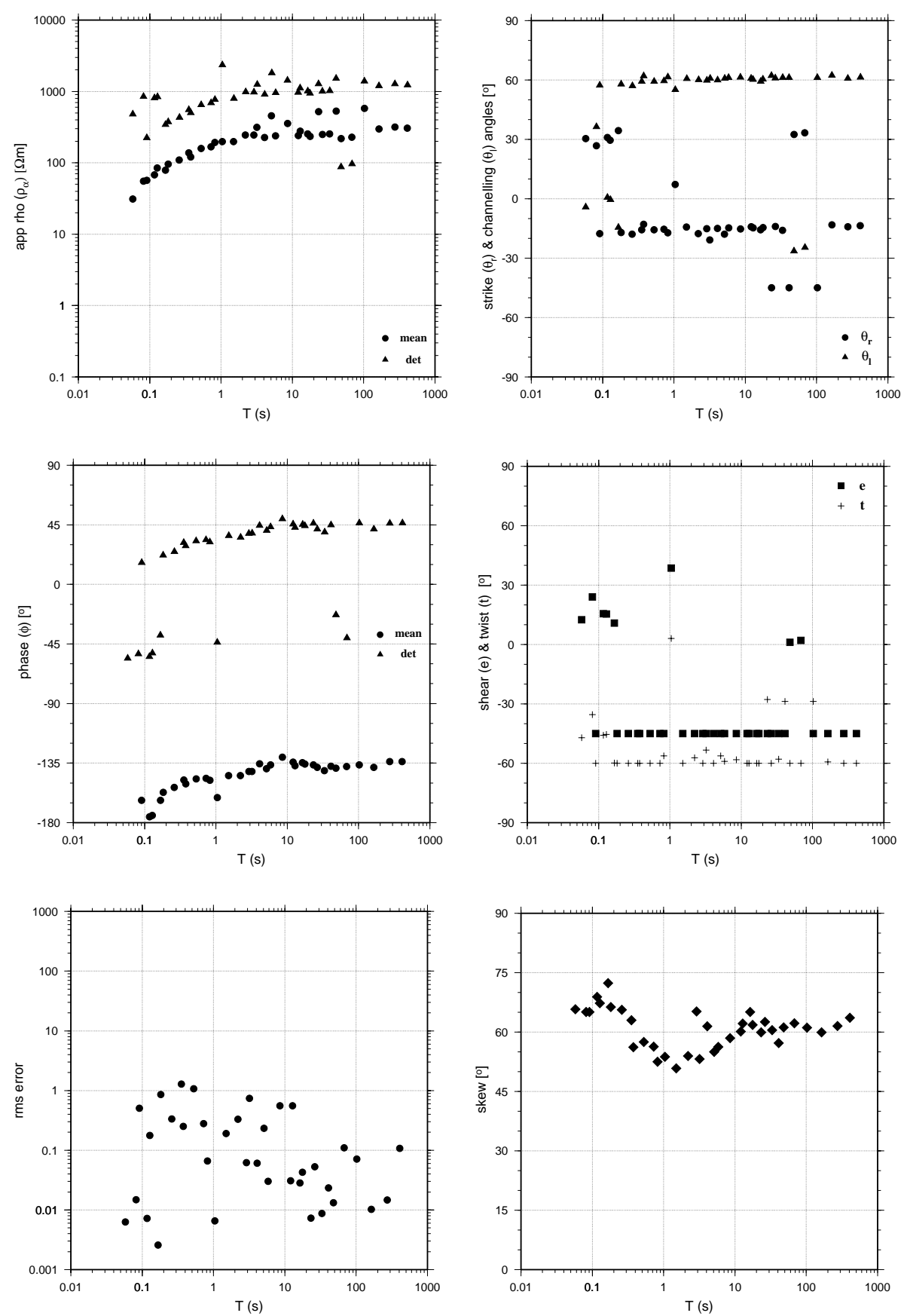

Fig. 2. Groom-Bailey decomposition parameters (regional strike: circles, local strike: triangles, shear: squares and twist values: crosses) of the impedance tensor for the SES station (PER). Swift's (1967) skew parameter is also depicted.

The Mohr circle technique is an elegant graphical method widely used in structural geology for analyzing stress variation in bodies (Ramsay and Huber, 1987). It is also applicable to the analysis of finite strain. The application of Mohr circles in MT interpretation was introduced by Lilley (1976). Nowadays, this simple technique is used to display the dimensionality of a structure and to infer the regional strike angle (Lilley, 1993, 1998a, b; Makris et al., 1999; Ingham et al., 2001). By simply rotating and then plotting specific rotated components of the measured impedance tensor (e.g.
$Z_{x x}^{\prime}$ vs. $Z_{x y}^{\prime}$ ) a circle is formed. A circle that is centered on the $Z_{x y}^{\prime}$-axis and has zero radius corresponds to a 1-D conductivity distribution, whereas a circle that is centered on the same axis but has a non-zero radius corresponds to a 2-D structure. In Mohr circle analysis separate regional strikes are determined for both the real and imaginary (quadrature) parts of the impedance tensor, while in the Groom-Bailey decomposition, a unique regional strike is calculated from the complex impedance tensor. 

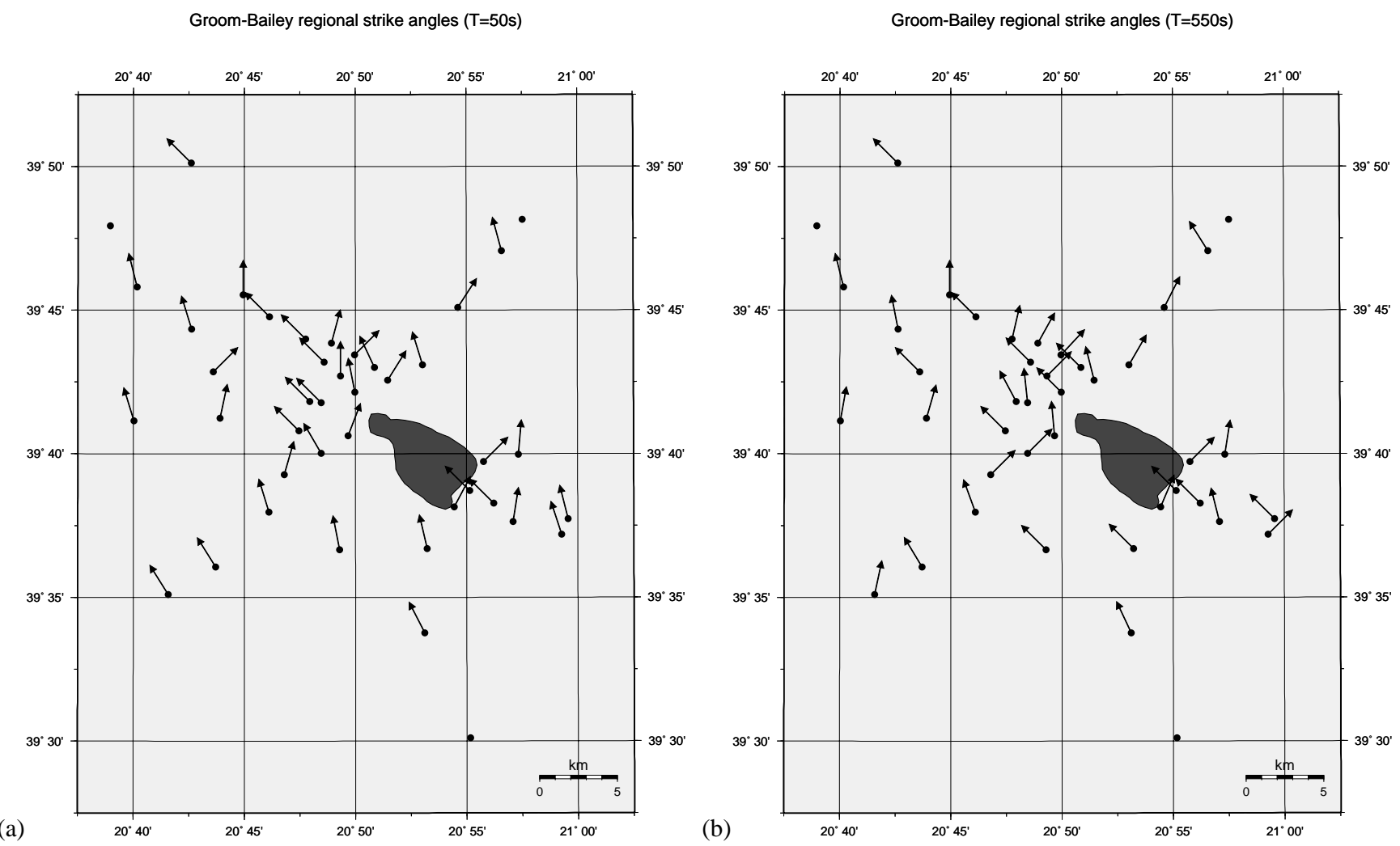

Fig. 3. Groom-Bailey decomposition regional strike angles at all sites, that the distortion model is valid, for $T=50,550 \mathrm{~s}$, respectively (a)-(b).

\subsection{Groom-Bailey decomposition}

A careful examination of our observations suggest a need to treat the Ioannina dataset for galvanic distortion. The initial check was carried out in terms of estimation of the rms error (misfit) of the data to a 2-D model as well as to a 3D (local)/2-D (regional) model (Groom-Bailey decomposition), and subsequent comparison of the two, for all 42 sites. The distortion model was found to be compatible with the MT data of 39 sites, however many of the sites where the decomposition model fit well exhibited shear angles close to $45^{\circ}$ (31 sites), which is evidence of strong distortion. The calculation of a unique regional strike angle for the Ioannina area proved impossible as the values of the calculated regional strike angles vary spatially across the survey area and with period (see Fig. 3a-b). In most cases, the derivation of a regional strike is difficult even for a single site, as there are significant deviations with period (Fig. 2).

\subsection{Mohr circles}

We can also examine dimensionality using Mohr circles to represent the MT responses. Makris et al. (1999), proposed the study of a conjugate form of the Mohr circle by replacing $Z_{x y}^{\prime}$ with $Z_{y x}^{\prime}$ in construction of the relevant circle. Such a representation allows, in some cases, for a more stable determination of the regional strike angle.

In this paper Mohr circle analysis is applied to all 42 sites of the Ioannina dataset. First, the standard Mohr circles, $Z_{x x}^{\prime}$ vs $Z_{x y}^{\prime}$, were constructed separately for the real and imaginary parts (circle groups with solid-line radii in Fig. 4a). An inspection of these circles shows that, for the frequency band under consideration (3-820 s), both the real and quadrature circles pass approximately through the origin at 35 sites. This orientation indicates that if we rotate the measuring system clockwise by an angle $\theta_{l}$ (i.e. the local strike angle), the elements of the first row of the (rotated) impedance tensor become both approximately zero: $Z_{x x}^{\prime}\left(\theta_{l}\right)=Z_{x y}^{\prime}\left(\theta_{l}\right)=0$, which physically means that irrespective of the polarization of the incident magnetic field, the electric field is linearly polarized in the direction of $y^{\prime}\left(\theta_{l}\right)$-axis.

We now turn to the conjugate form of the magnetotelluric representation of Mohr circles, $Z_{x x}^{\prime}$ vs $Z_{y x}^{\prime}$ (circle groups with dashed-line radii in Fig. 4a). These circles exhibit the same configuration, i.e. they pass through the origin for the same 35 sites regardless of the period or whether one considers the real or imaginary parts. This behavior, however, is expected, since the conjugate Mohr circles is just the exact mirror image of the traditional circle with respect to the vertical coordinate axis. This characteristic implies that, if we rotate clockwise the measuring system by an angle $\theta_{r}$ the elements of the first column of the (rotated) impedance, i.e. $Z_{x x}^{\prime}\left(\theta_{r}\right)$ and $Z_{y x}^{\prime}\left(\theta_{r}\right)$, both become approximately zero. Consequently, we reach the following physical explanation: the incidence of a magnetic field linearly polarized in the direction $x^{\prime}\left(\theta_{r}\right)$ does not induce an electric field; this result corresponds to the TM mode of a 2-D regional structure 
(a)

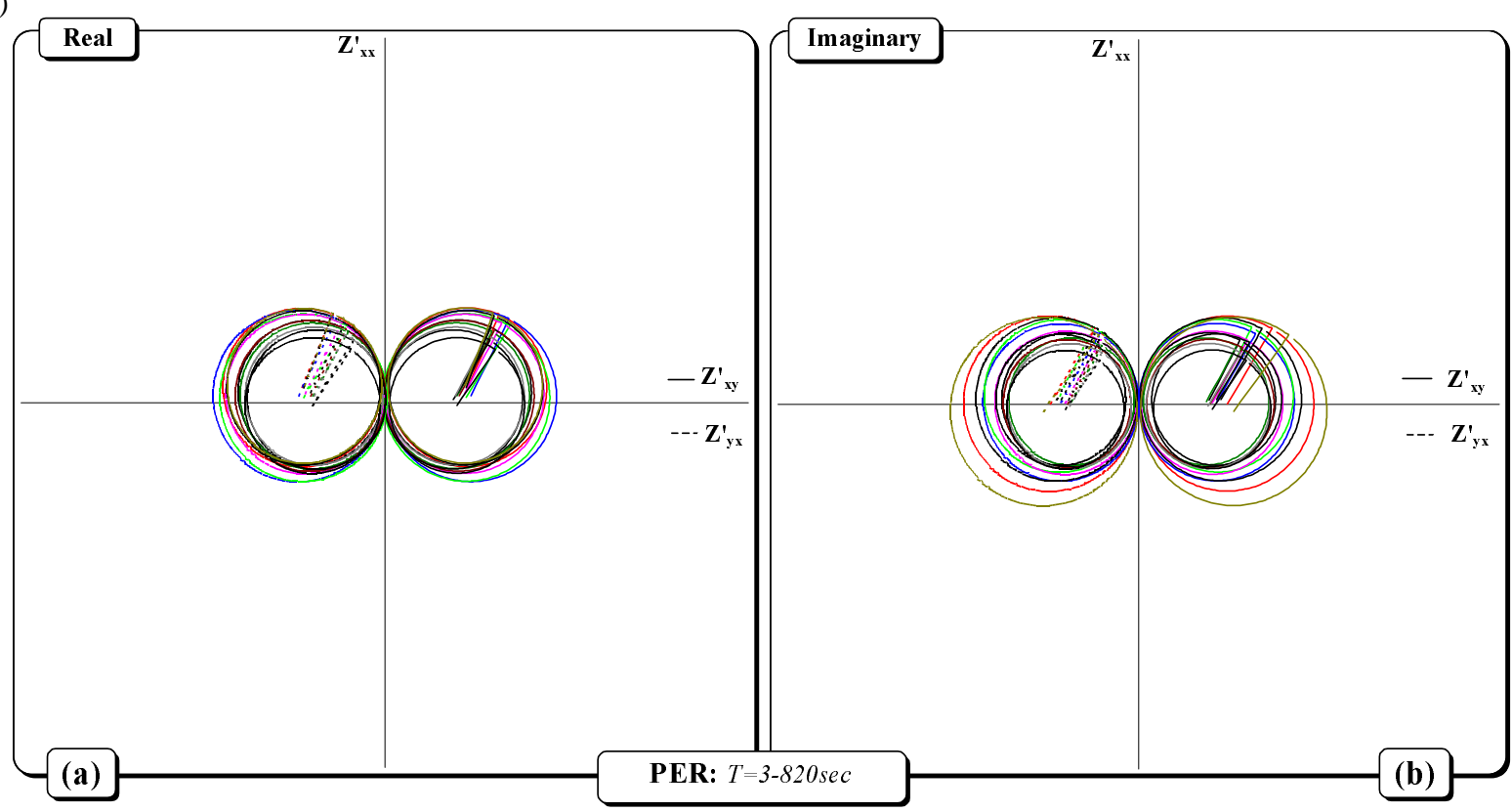

(b)

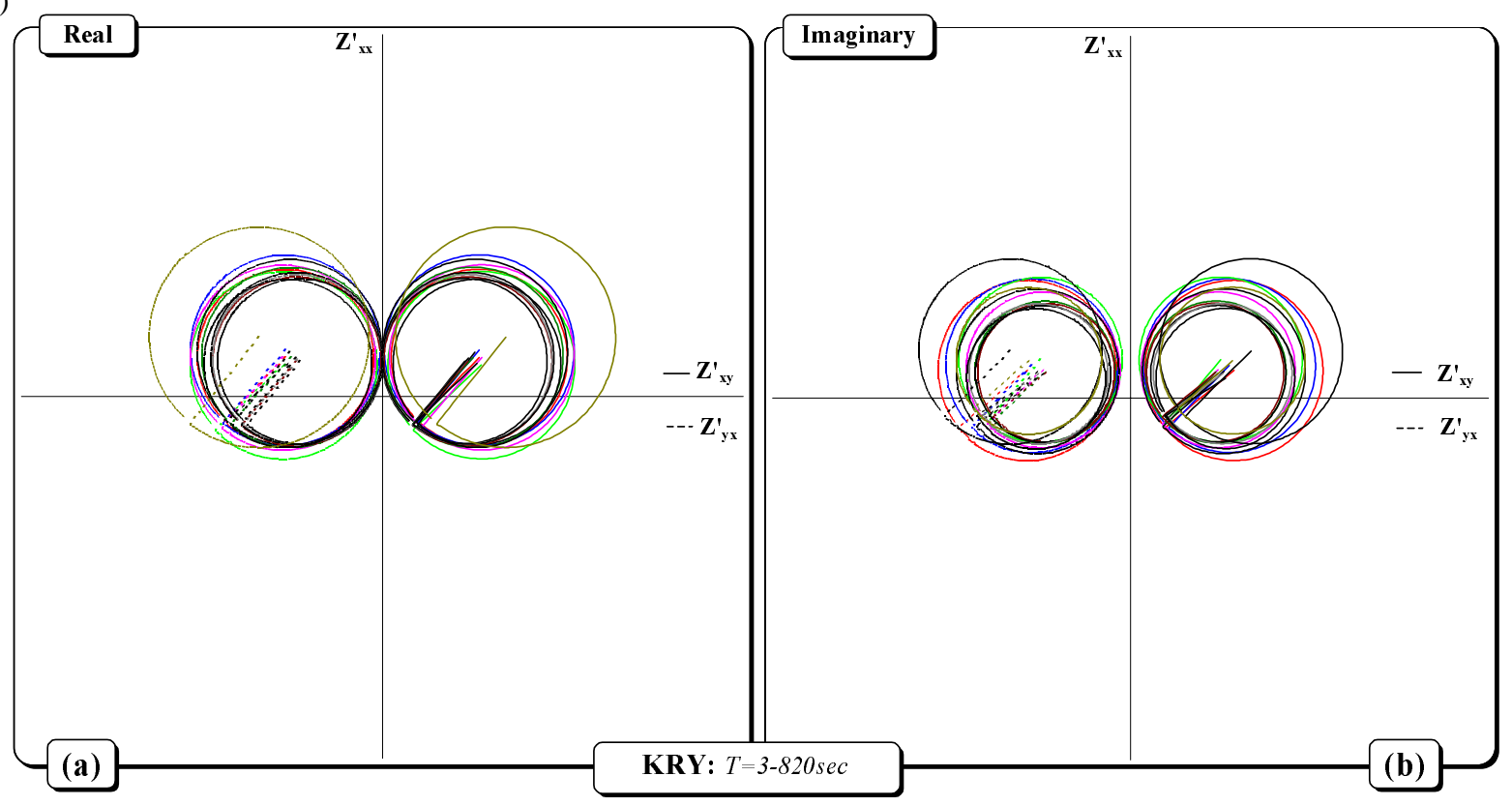

Fig. 4. Mohr circles at various periods $(T=3-820 \mathrm{~s})$, by taking (a) the real and (b) the quadrature parts of the $Z_{x x}^{\prime}$ vs. $Z_{x y}^{\prime}$ impedance tensor elements (circle groups with solid-line radii) and of the $Z_{x x}^{\prime}$ vs. $Z_{y x}^{\prime}$ impedance tensor elements (circle groups with dashed-line radii), determined from MT data from sites PER and KRY, respectively. (The impedance values for these sites have been normalized by multiplication by $\sqrt{T}$; thus apparent resistivities are depicted instead of impedances in the corresponding Mohr circles.)

with highly anisotropic responses (e.g. a vertical conductivity boundary, where the measuring site lies on the conductive medium but close to the resistivity contrast). In this case the magnetic field polarization direction indicates the 2-D regional strike direction. The significance of the aforementioned statement depends on the stability of the rotation angle $\theta_{r}$ upon changing the measuring site, the period, and the consideration of either the real or the imaginary parts. In Fig. 5a-b the regional strike angles calculated from the method are depicted for the sites where circles pass through the origin for both the real and imaginary impedances at periods of 50 and $550 \mathrm{~s}$, respectively. The regional strike angles derived independently from both the real and imaginary parts of the impedance tensor agree well and provide consistent results. From these plots we resolve a regional strike direction of approximately $\mathrm{N} 35^{\circ} \mathrm{W}$ for these 35 sites within the Ioannina area. 


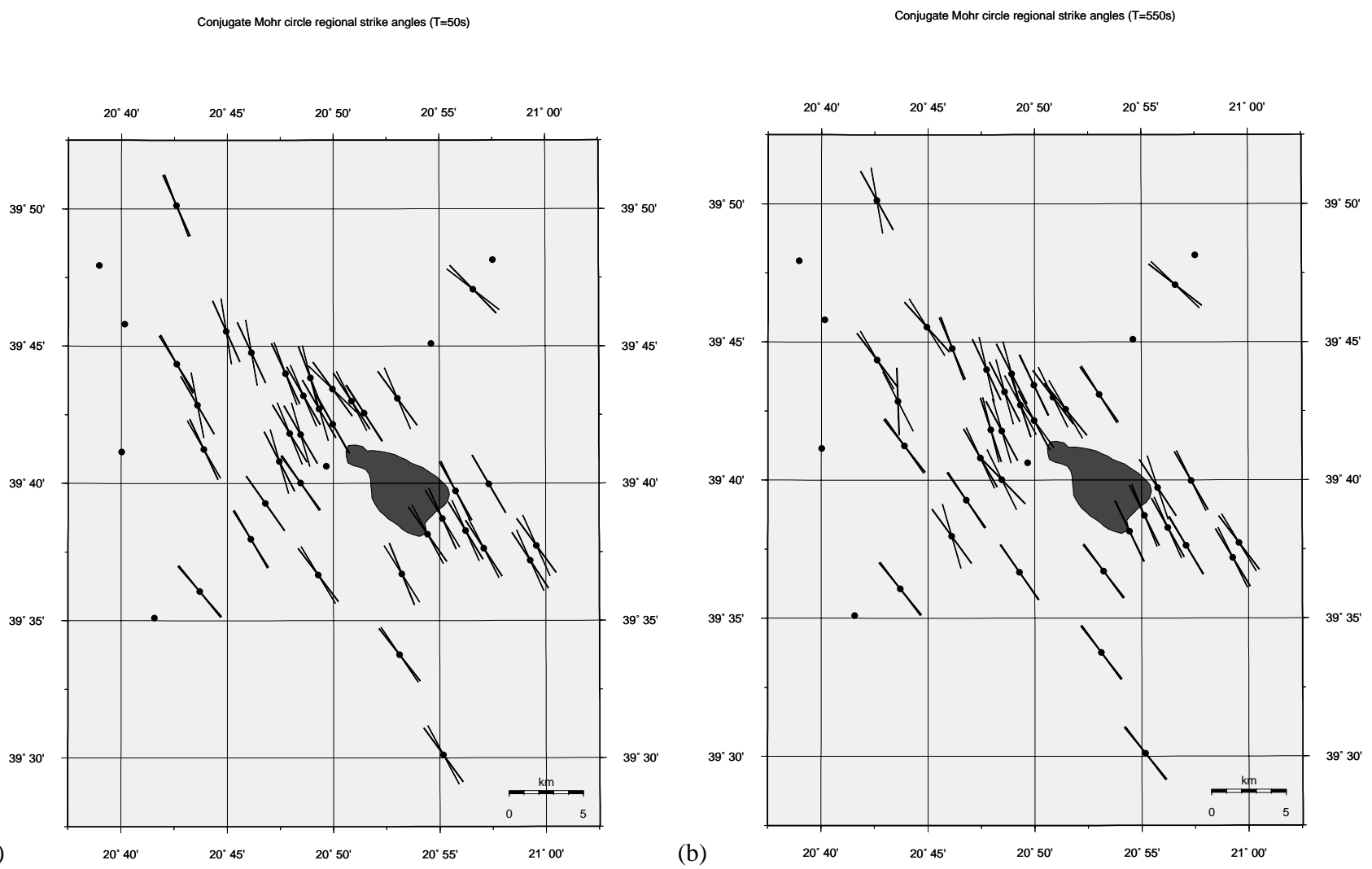

(a)

Fig. 5. Mohr circles regional strike angles at all sites, that circles pass through the origin, for $T=50,550 \mathrm{~s}$, respectively (a)-(b) (bold lines stand for regional strike inferred from the real part whereas thin lines from the quadrature parts).

For the Ioannina dataset, Groom-Bailey decomposition fails to derive a regional strike, while the Mohr circle technique provides a clear estimation of the regional strike. The validity of the result is strengthened by the agreement between independent regional strike directions inferred from the real and imaginary parts of the impedance tensor, as well as the high spatial uniformity of the strike direction. This is probably due to the fact that standard decomposition methods are more focused on the characteristics of the local galvanic scatterers whereas the Mohr circle technique emphasizes properties of the regional structure.

The sites of the Ioannina dataset where Mohr circles do not pass through the origin exhibit a different behavior (e.g. Fig. $4 b$ ), tend to be located along the edges of the survey region, and likely reflect changes in the regional conductivity structure outside of the central Ioannina platform (see points without regional strike calculation in Fig. 5a-b and triangles in Fig. 1c).

\section{Magnetic distortion analysis of the Ioannina magnetic response functions}

A basic limitation of techniques such as Groom-Bailey decomposition and Mohr circle analysis is that they are based upon single-station impedance tensor measurements. When we attempt to extract conclusions from an MT survey such as regional strike, we often experience difficulty in defining a unique azimuth for our structure. There are other techniques that examine the regional behavior of the electromagnetic response. GDS surveys, with their 2-D spatial coverage, are a valuable means of detecting sharp conductivity boundaries through the charges built up on them and the resulting electric current distortions they create. As such, GDS data provide an independent picture of the geometry of regional conductors. In the GDS method, the relationship between the vertical and the horizontal components of the magnetic field is given by

$H_{z}=(\mathcal{A}, \mathcal{B}) \mathbf{H}_{h}=\mathcal{A} H_{x}+\mathcal{B} H_{y}$,

where $(\mathcal{A}, \mathcal{B})$ is the vertical magnetic response function.

The magnetic response functions are typically viewed as induction arrows, which are a projection of the magnetic field onto the $x y$-plane (Schmucker, 1970). They are typically presented as real and imaginary arrows and their directions provide information about the subsurface conductivity structure. They in general point perpendicular to the direction of current flow, i.e. a conductivity boundary, and their lengths can be interpreted as a measure of the lateral conductivity gradient.

On the assumption that galvanic distortion is caused by small-scale near-surface inhomogeneities, e.g. a $100 \mathrm{~m}$ radius conductive hemisphere located at the surface (Groom 

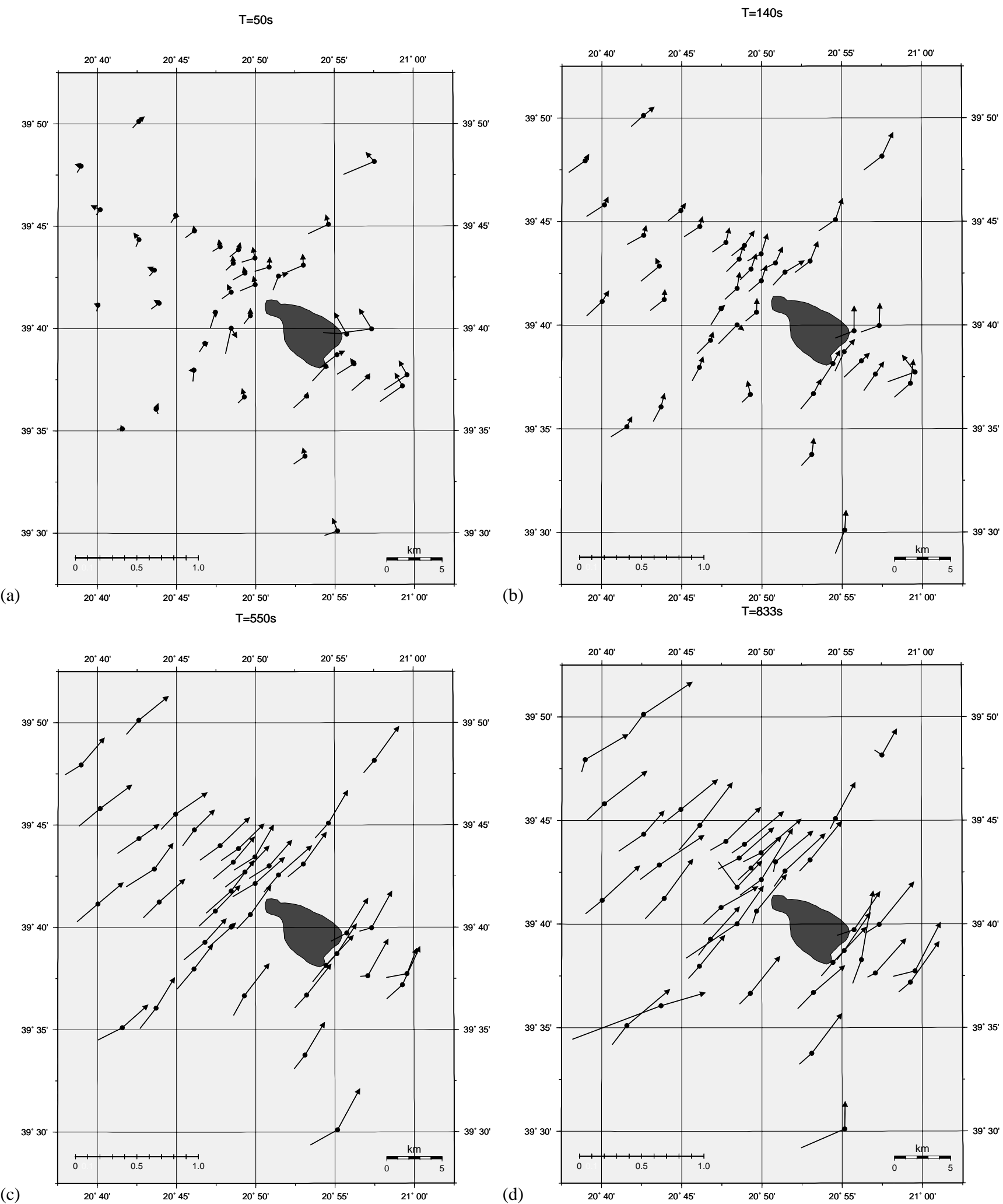

Fig. 6. Induction arrows at $T=50,140,550$ and $833 \mathrm{~s}$ (Wiese convention), respectively (a)-(d). (Arrows indicate real and lines imaginary induction arrows.)

and Bailey, 1991), magnetic distortion is observed only at high frequencies $(\omega>100 \mathrm{~Hz})$ and can be neglected at lower frequencies (Ritter, 1996). At longer periods, however, upper- and mid-crustal structures with an extent of $10 \mathrm{~km}$ or more are smaller than the skin-depth of the impinging electromagnetic waves and the major influence in this period 
range may take the form of magnetic distortion rather than induction (Chave and Smith, 1994; Ritter, 1996; Ritter and Banks, 1998).

In the frequency range where distortion dominates, the length and direction of induction arrows may be controlled by the anomalous magnetic field due to locally-deflected regional currents (Ritter, 1996). As a consequence, induction arrows may indicate neither the local strike, nor the regional one, but rather a mixture of the two (Gurk, 1999). As opposed to induction arrows and galvanic distortion techniques, Hypothetical Event Analysis (HEA) of the magnetic response functions treats the dataset as a whole, thus enabling us to define the dimensionality of the structure and to correct for such distortion phenomena, leading to a more robust determination of regional strike.

\subsection{Induction arrows}

We note that the area of measurements is located approximately $50 \mathrm{~km}$ from the Ionian Sea (Fig. 1b). It is therefore expected that the influence of the coastline, a largescale conductivity contrast, will be observed in the magnetic field within a certain period range (coast effect, Schmucker, 1970). As this survey is located along an active continental margin, large-scale subparallel structural features, such as the Pindus Range, may also influence the induction vectors at long periods.

The induction arrows at relatively short periods (Wiese convention, Wiese, 1962) for the Ioannina dataset are shown in Fig. 6a. At this period there is no evidence of the coast effect in the magnetic field data, which largely reflect conductivity structure within the survey area. However, as we proceed to longer periods the influence of regional conductivity structure, together with the coast effect is increasingly evident in the data, with induction vectors pointing away from the coastline. In Fig. 6b-d at $T=140,550$ and $833 \mathrm{~s}$ both real and imaginary induction vectors exhibit very consistent directions and magnitudes which indicate a strike direction of $\mathrm{N} 45^{\circ} \mathrm{W}$. This regional structure direction matches both the coastline and geological structures which follow the coast. In the absence of detailed modeling of the continental margin, it is not possible to assess how much of the observed induction arrows behavior is due to the coastline as opposed to regional geologic structure.

\subsection{Hypothetical event analysis}

The distorted magnetic response function is given by (Ritter, 1996)

$$
(\mathcal{A}, \mathcal{B})=\left[\left(\mathcal{A}^{0}, \mathcal{B}^{0}\right)+\left(\mathcal{A}^{\ell}, \mathcal{B}^{\ell}\right)\right]
$$

where $\left(\mathcal{A}^{0}, \mathcal{B}^{0}\right)$ express the regional and $\left(\mathcal{A}^{\ell}, \mathcal{B}^{\ell}\right)$ the local magnetic response functions.

Let us consider the case of the TM mode, in which the horizontal magnetic field is directed parallel to the coastline. The vertical magnetic field transfer function is expected to vanish for this mode, and thus a non-zero transfer function

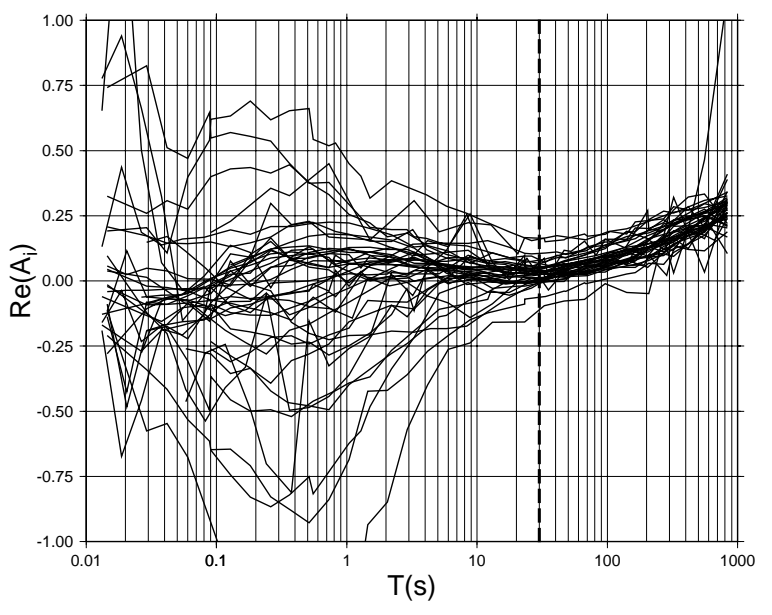

Fig. 7. Magnetic distortion test for the real part of the $\mathcal{A}$ component of the magnetic response function at all sites.

indicates anomalous fields resulting from magnetic distortion.

In order to identify the period range over which current distortion is the cause of anomalous vertical magnetic fields, we examine the variation of the magnetic response function components of all sites (Ritter, 1996). The curves for the component $\mathcal{A}_{i}(T)$ ( $i$ is the site and $T$ is the period), for example, will have different shapes in the period range of induction $\left(\mathcal{A}_{i}(T)=\mathcal{A}_{i}^{0}(T)\right)$, whereas they run parallel over the periods where galvanic distortion is the dominant process $\left(\mathcal{A}_{i}(T) \approx \mathcal{A}_{i}^{\ell}(T)\right)$. This is because the ratio will be, for two different sites $i$ and $j$ (Ritter and Banks, 1998),

$\frac{\mathcal{A}_{i}^{\ell^{\prime}}(T)}{\mathcal{A}_{j}^{\ell^{\prime}}(T)}=\frac{D_{z y}^{\prime}\left(\mathbf{r}_{i}\right)}{D_{z y}^{\prime}\left(\mathbf{r}_{j}\right)}$

which is a real number. The prime denotes regional coordinates, $D_{z y}^{\prime}$ is a real magnetic distortion coefficient and $\mathbf{r}_{i, j}$ are the vectors of position. It is clear from the magnetic response functions in Fig. 7 that magnetic distortion primarily occurs for $T>30 \mathrm{~s}$. For this reason, our analysis is focused in this period range.

The HEA method calculates the predicted vertical magnetic field, $H_{z}^{p}$, at all stations that would be associated with a hypothetical event which has a uniform external horizontal field, $\mathbf{H}_{h}^{*}$ of specified polarization. Since the hypothetical external field is uniform, any variations in $H_{z}$ from station to station must be of internal origin, the result of local channeling or induction (Bailey et al., 1974). As a multi-station method, HEA performs an overall analysis of the dataset and is well-suited to identifying characteristics of the regional structure. In practice, a predicted vertical magnetic field $H_{z}^{p}$ is estimated from the observed magnetic response function by assuming a horizontal magnetic field of unit amplitude and polarization $\vartheta^{*}$

$H_{z}^{p}=(\mathcal{A}, \mathcal{B}) \mathbf{H}_{h}^{*}=(\mathcal{A}, \mathcal{B})\left[\begin{array}{l}1 \cdot \cos \vartheta^{*} \\ 1 \cdot \sin \vartheta^{*}\end{array}\right]$ 
Pred. $\operatorname{Ke}\left(\mathrm{H}_{\mathrm{z}}\right)[\mathrm{n} I]$

rrea. $\operatorname{Ke}\left(\mathrm{H}_{\mathrm{z}}\right)\lfloor\mathrm{n} I\rfloor$

$\begin{array}{llllllllll}-0.50 & -0.25 & 0.00 & 0.25 & 0.50 & -0.50 & -0.25 & 0.00 & 0.25 & 0.50\end{array}$
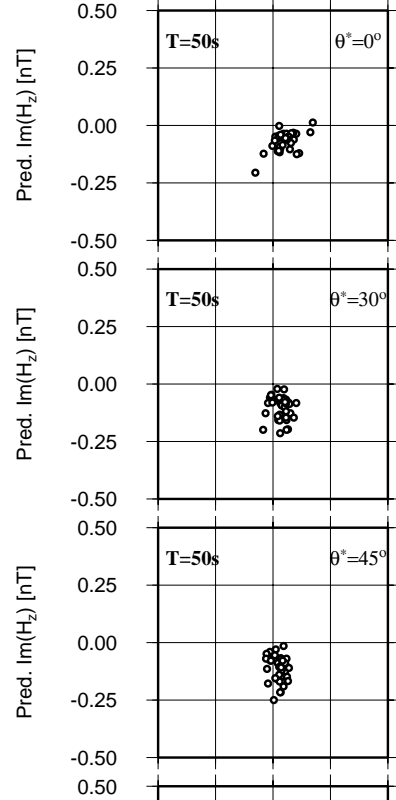

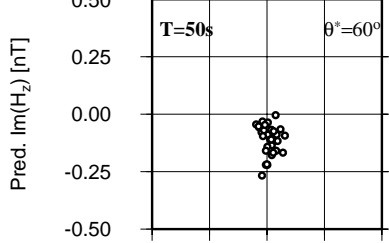

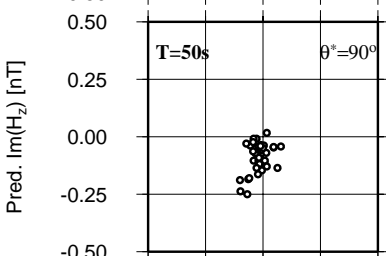

$-0.50$

$\begin{array}{lllll}0.50 & -0.25 & 0.00 & 0.25 & 0.50\end{array}$

Pred. $\operatorname{Re}\left(\mathrm{H}_{\mathrm{z}}\right)[\mathrm{nT}]$
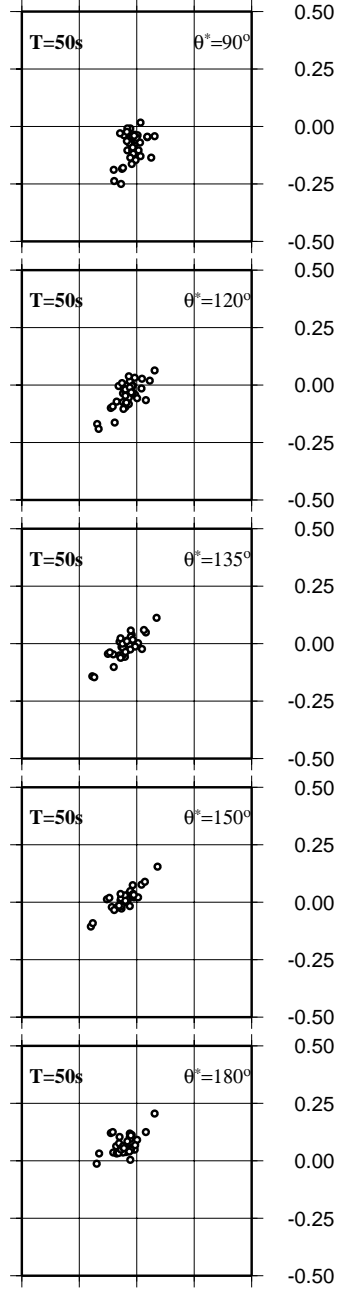

$-0.50$

(a)

)

$\begin{array}{llllll}0 & -0.50 & -0.25 & 0.00 & 0.25 & 0.50\end{array}$

Pred. $\operatorname{Re}\left(\mathrm{H}_{\mathrm{z}}\right)[\mathrm{nT}]$

0.25 .50

0.25

0.00

$-0.25$

0.50

0.25
0.00

$-0.25$

$-0.50$
Pred. $\operatorname{Ke}\left(\mathrm{H}_{\mathrm{z}}\right)[\mathrm{nI}]$

rrea. $\operatorname{Ke}\left(\mathrm{H}_{\mathrm{z}}\right)\lfloor\mathrm{nI}\rfloor$

$\begin{array}{llllllllll}-0.50 & -0.25 & 0.00 & 0.25 & 0.50 & -0.50 & -0.25 & 0.00 & 0.25 & 0.50\end{array}$

E

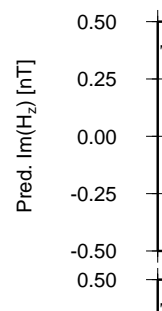
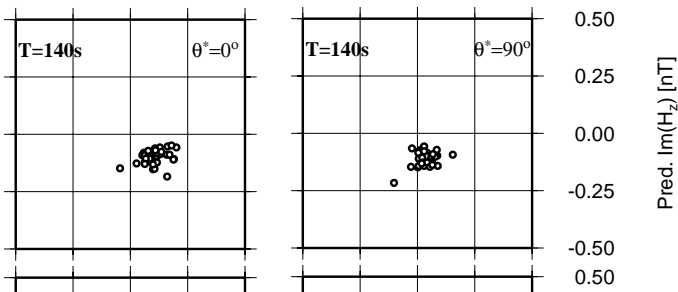

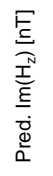

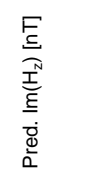

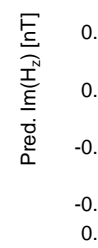

\begin{tabular}{ll|l|l|l|l|} 
& $\mathrm{T}=140 \mathrm{~s}$ & & $\theta^{*}=30^{\circ}$ \\
\hline & & & & \\
\hline \\
\cline { 2 - 6 } & & & & & \\
\hline
\end{tabular}

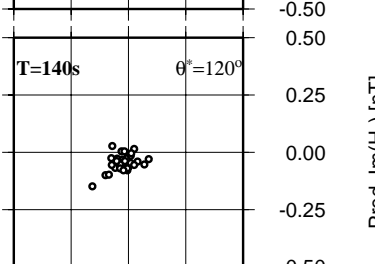

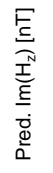

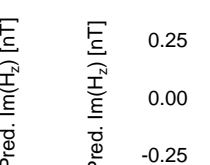
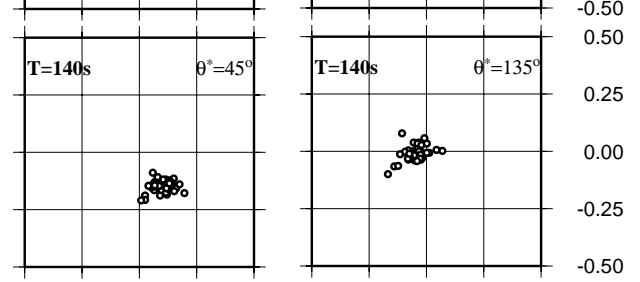

E

$\frac{\text { E }}{\stackrel{T^{N}}{E}}$

के

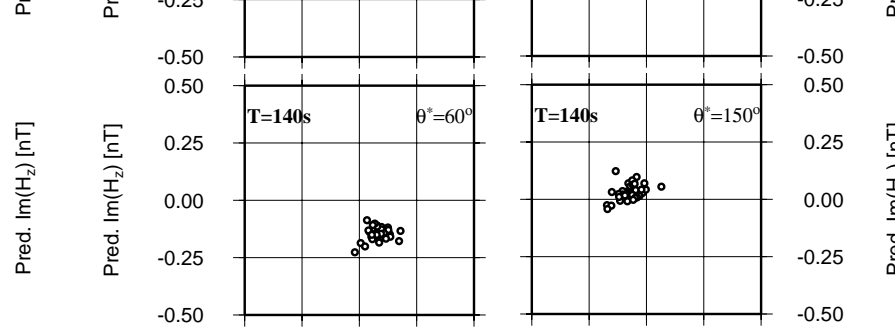

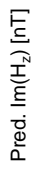

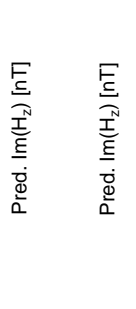

(b)
0.50

0.25

0.00

$-0.25$

$-0.50$

$\begin{array}{lllll}-0.50 & -0.25 & 0.00 & 0.25 & 0.50\end{array}$

Pred. $\operatorname{Re}\left(\mathrm{H}_{\mathrm{z}}\right)[\mathrm{nT}]$

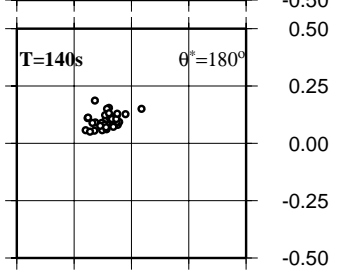

Pred. $\operatorname{Re}\left(\mathrm{H}_{\mathrm{z}}\right)[\mathrm{nT}]$

Fig. 8. Argand diagrams of $H_{z}^{p}$ at $T=50,140,550$ and $833 \mathrm{~s}$ (a)-(d) for polarization angles $\vartheta^{*}=0^{\circ}, 30^{\circ}, 45^{\circ}, 60^{\circ}$ and $90^{\circ}($ left column) and perpendicular to these (right column). (The periods of analysis are the same as in Fig. 6a-d). Argand diagram at $T=50 \mathrm{~s}$ (e) but with polarization angles $\vartheta^{*}=30^{\circ}, 35^{\circ}, 40^{\circ}, 45^{\circ}$ and $50^{\circ}$ (left column) and perpendicular to these (right column).

In the case of purely 2-D Earth structure, the distribution of values of the predicted vertical magnetic field in an Argand diagram is highly dependent on the azimuth of polarization (Ritter, 1996). There should exist, however, an angle where the values of $H_{z}^{p}\left(\vartheta^{*}\right)$ and $H_{z}^{p}\left(\vartheta^{*}+\pi / 2\right)$ collapse on a distinct phase line. If the phase line is shifted away from the origin, we must assume that a regional vertical magnetic component is present in the data. Upon varying the polarization azimuth, the shift can be eliminated; it vanishes if the hypothetical horizontal field is polarized parallel to the regional strike direction. HEA is therefore able to remove the anomalous vertical magnetic component and the gradient of this line indicates the phase of one of the regional impedances $\left(Z_{T M}\right.$, i.e. the TM mode impedance). Indeed, when the polarization angle equals the regional strike direc- tion it is proven that, in the case of the TM mode (Ritter and Banks, 1998)

$\vartheta^{*}=\theta_{r}: \quad H_{z}^{p}=D_{z x}^{\prime \prime} Z_{T M} \sin \left(\theta_{l}-\theta_{r}\right)$,

where $D_{z x}^{\prime \prime}$ is a real number expressing magnetic distortion in local coordinates.

From the Argand diagrams of Fig. 8b-d we observe that at longer periods $(T>100 \mathrm{~s})$ there is a consistent, regional 2$\mathrm{D}$ inductive response corresponding to a strike direction of $\mathrm{N} 45^{\circ} \mathrm{W}\left(H_{z}^{p}\right.$ is clustering around zero for $\vartheta^{*}=135^{\circ}$, as is expected from Eq. (6), and the maximum response (largest anomalous field) is observed for $\vartheta^{*}=45^{\circ}$; these angles are measured with respect to the trigonometric circle). We suspect that distortion/scattering effects are also present at the longer periods, but are small compared with the inductive response of the large-scale structure, and show up as scatter in 
Pred. $\operatorname{Ke}\left(\mathrm{H}_{\mathrm{z}}\right)\lfloor\mathrm{nI}$

rrea. $\operatorname{Ke}\left(\mathrm{H}_{\mathrm{z}}\right)\lfloor\mathrm{n} \mathrm{I}$

$\begin{array}{llllllllll}-0.50 & -0.25 & 0.00 & 0.25 & 0.50 & -0.50 & -0.25 & 0.00 & 0.25 & 0.50\end{array}$
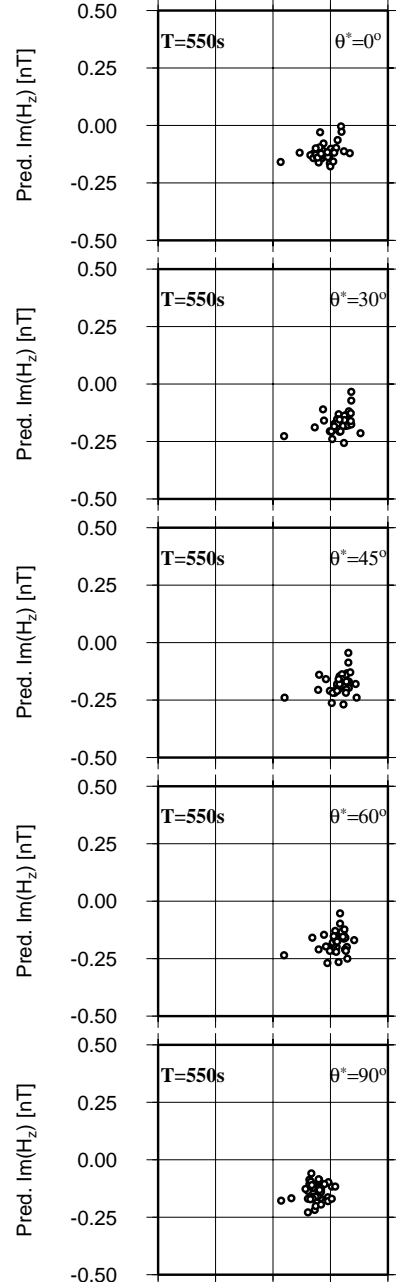

$\begin{array}{lllll}-0.50 & -0.25 & 0.00 & 0.25 & 0.50\end{array}$

Pred. $\operatorname{Re}\left(\mathrm{H}_{\mathrm{z}}\right)[\mathrm{nT}]$

(c)
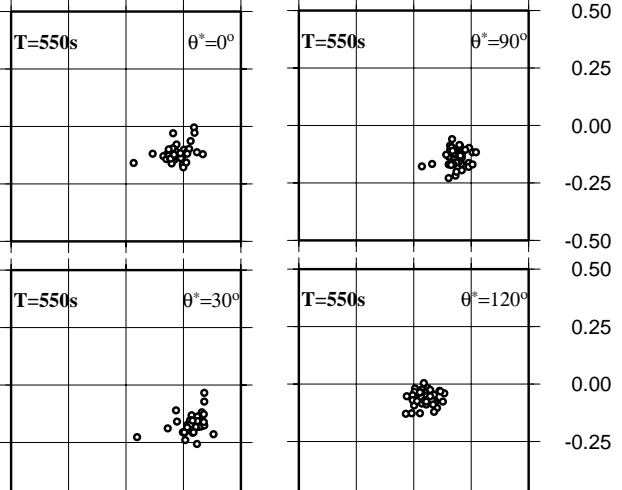

0.25

0.00

$-0.25$
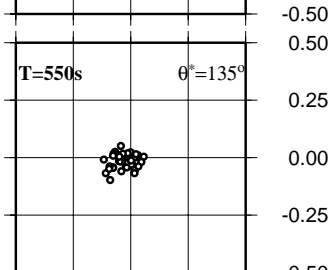

0.50

0.25

0.00
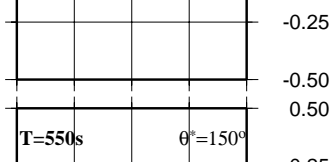

0.25

$-0.25$
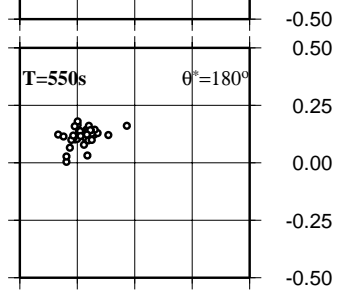

$-0.50$

Pred. $\operatorname{Re}\left(\mathrm{H}_{\mathrm{z}}\right)[\mathrm{nT}]$
Pred. $\mathrm{Ke}\left(\mathrm{H}_{\mathrm{z}}\right)[\mathrm{nI}$

Prea. $\operatorname{Ke}\left(\mathrm{H}_{\mathrm{z}}\right)\lfloor\mathrm{n} \mathrm{I}$

$\begin{array}{llllllllll}-0.50 & -0.25 & 0.00 & 0.25 & 0.50 & -0.50 & -0.25 & 0.00 & 0.25 & 0.50\end{array}$

E

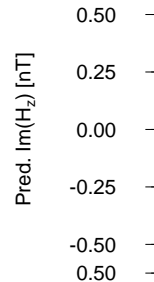

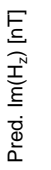

E

E

0.50
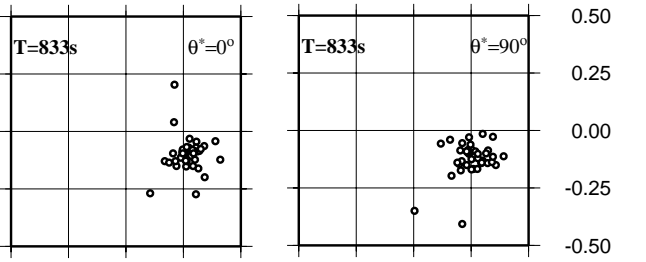

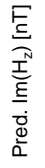
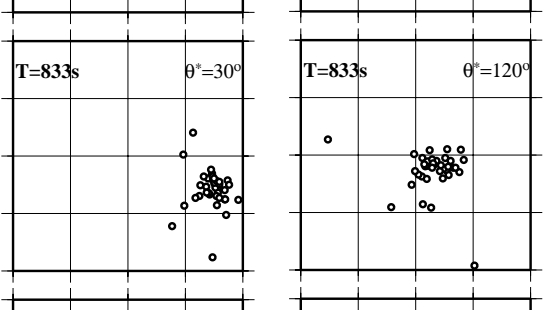

0.50

E
N
I
Eे
Dं
D.
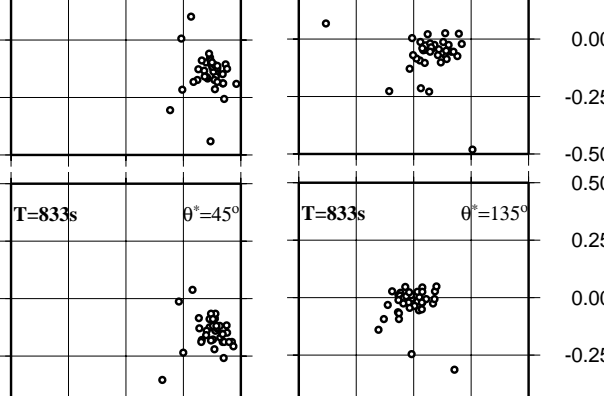

\begin{tabular}{ll|l|l}
\hline & & & -0.25
\end{tabular}
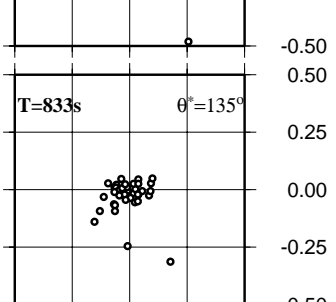

0.25

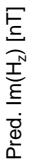

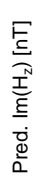

0.50

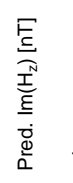

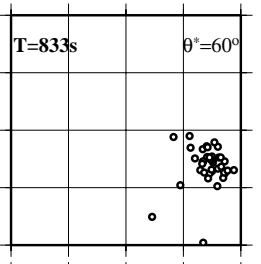

0.50
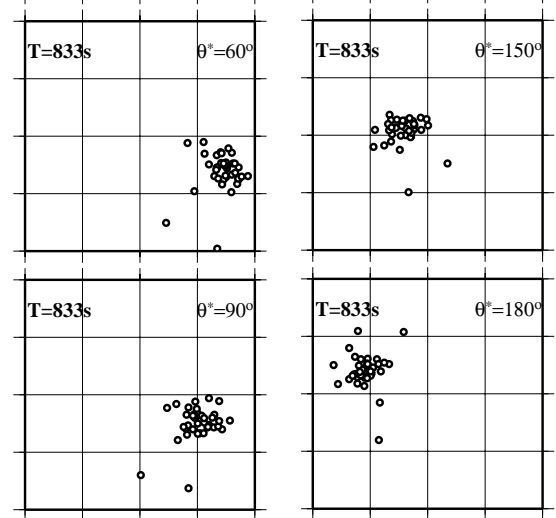

$-0.50$

0.50

0.25

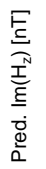

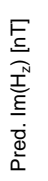

$-0.50$

$\begin{array}{lllll}-0.50 & -0.25 & 0.00 & 0.25 & 0.50\end{array}$

Pred. $\operatorname{Re}\left(\mathrm{H}_{\mathrm{z}}\right)[\mathrm{nT}]$

Pred. $\operatorname{Re}\left(\mathrm{H}_{\mathrm{z}}\right)[\mathrm{nT}]$

Fig. 8. Continued.

the response on the Argand diagrams. This result is in good agreement with induction arrows interpretation (Fig. 6b-d). We now apply HEA at $T=50 \mathrm{~s}$ which is a characteristic period of distortion. In Fig. 8a we observe that for $\vartheta^{*}=135^{\circ}$ the experimental points form a line that passes through the origin. In order to determine the regional strike more precisely we apply HEA at $T=50 \mathrm{~s}$ for polarization azimuths in a narrower angular interval (Fig. 8e). Within the error limitations of the method we conclude for the polarization angle a mean value $\vartheta^{*}=135^{\circ}$; this corresponds to a strike angle of $\mathrm{N}^{\circ} 5^{\circ} \mathrm{W}$. The latter implies that when current flows perpendicular to the regional strike there is local scattering by structures which must have components in the direction of the current flow, i.e. perpendicular to the regional strike. Additionally, the phase of the TM mode should be roughly $45^{\circ}$, while the phase of the TE mode is $\sim 90^{\circ}$ - quite different and presumably dominated by the regional induction process. We are thus able to evaluate the regional strike angle for periods $T \geq 50 \mathrm{~s}$, in contrast to induction arrows which only define the regional strike for periods $T \geq 140 \mathrm{~s}$.

We can furthermore generate maps of the real and imaginary parts of $H_{z}^{p}$ at $T=50 \mathrm{~s}$ corresponding to $\vartheta^{*}=135^{\circ}$ (Fig. 9a-b, respectively). The choice of $\vartheta^{*}$ eliminates the regional structure allowing us to see the effects of scatterers more clearly (R. Banks, personal communication, 2000). Figure $9 \mathrm{a}-\mathrm{b}$ indicate the existence of a number of magnetic anomalies, in terms of strong gradients of the magnetic field (extreme values of real and imaginary $H_{z}^{p}$ ); the strongest anomalies are observed at sites LOG and MAZ near Ioannina lake, M99-VOU to the west of the lake and at PER to the north of the lake. These anomalies are observed in both the real and imaginary hypothetical event maps. It is noteworthy that the Ioannina SES station (PER) lies above a strong gradient of the magnetic field. 
Pred. $\operatorname{Ke}\left(\mathrm{H}_{\mathrm{z}}\right)\lfloor\mathrm{nI}$

rrea. $\operatorname{Ke}\left(\mathrm{H}_{\mathrm{z}}\right)\lfloor\mathrm{n}$ I!

$\begin{array}{llllllllll}-0.50 & -0.25 & 0.00 & 0.25 & 0.50 & -0.50 & -0.25 & 0.00 & 0.25 & 0.50\end{array}$

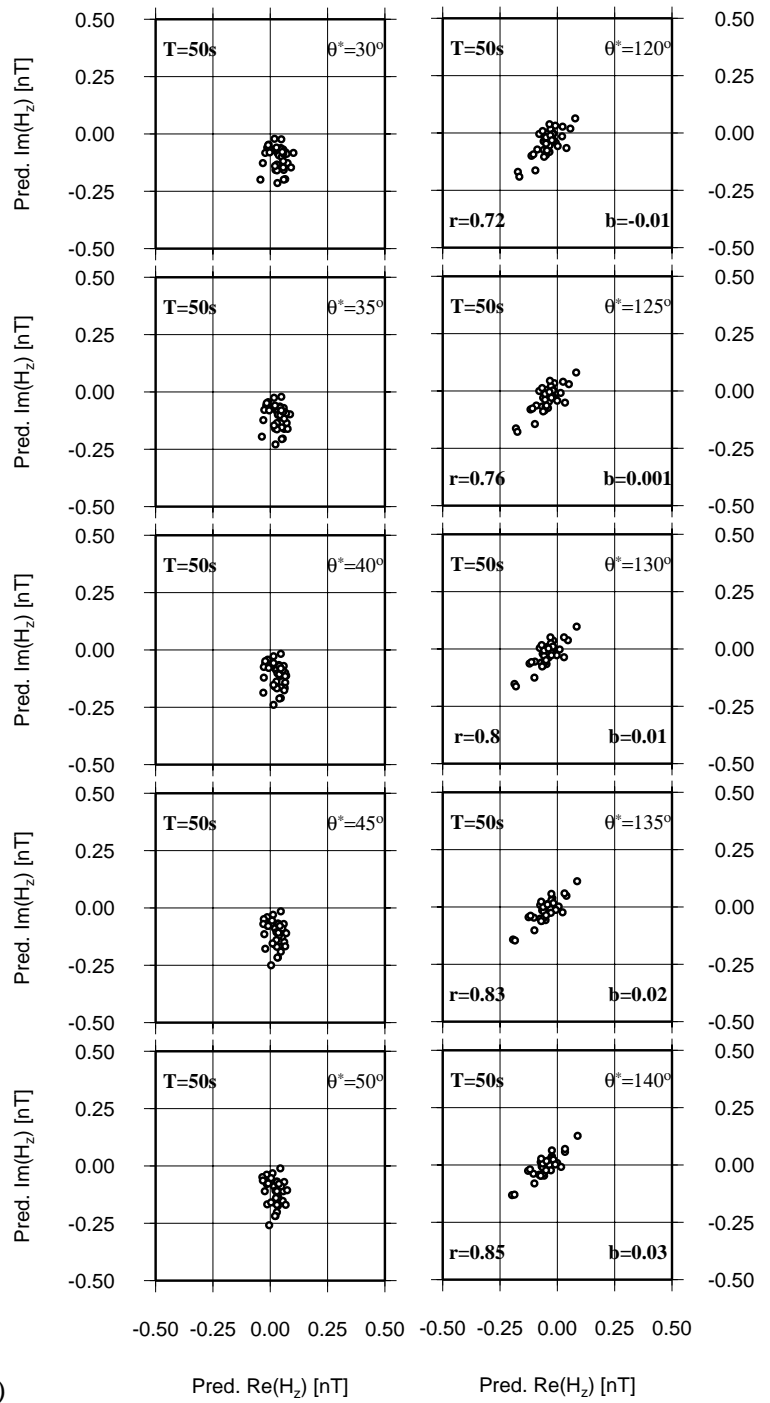

Fig. 8. Continued.

\section{2-D inversion of the MT data}

The MT impedance data, upon rotation to $\mathrm{N} 45^{\circ} \mathrm{W}$, are presented in the form of pseudosections of apparent resistivity and phase plotted against the $\log$ of the frequency, which serves as a measure of the relative depth of penetration of the electromagnetic field (Banks et al., 1996). The apparent resistivity sections can be affected by static shifts which scale the apparent resistivity values up or down at a site relative to its neighbours, depending on lateral variations in the conductivity of the near-surface layers (Banks et al., 1996). The phase data, however, are unaffected and reveal more clearly the laterally persistent features of the deeper structure. In quasi-layered portions of the structure, phase values exceeding $45^{\circ}$ identify regions where the resistivity is decreasing with depth, while low values $\left(<45^{\circ}\right)$ correspond to regions where it is increasing (Banks et al., 1996).
TE and TM mode pseudosections of apparent resistivities and phase along a SW-NE oriented profile crossing the Ioannina platform (see Fig. 9) are presented in Fig. 10a-d. The profile is $35 \mathrm{~km}$ long and consists of a subset of 14 sites. At short periods, apparent resistivities are generally high along the central part of the profile, decreasing toward the ends. A rise in phase around $10 \mathrm{~s}$ is observed at most sites along the profile, corresponding to a decrease in resistivity at midcrustal depths.

Upon inverting the data using the nonlinear conjugategradient inversion algorithm of Rodi and Mackie (2001), the 2-D model in Fig. 11 is obtained. The model fits the TE and TM apparent resistivity and phase data to an r.m.s. misfit of 2.29 , given errors of $10 \%(5 \%)$ in apparent resistivity (phase). The regularization parameter, tau, was set at 3 based on a series of trial inversions in which tau was varied from $1-100$. In general, the model is quite resistive $(>500 \Omega m)$, with more conductive regions confined to the edge of the model. This first order picture is in agreement with surface geology and regional tectonics, as discussed in more detail in Bedrosian and Balasis (2005) ${ }^{1}$. In the resistivity model presented here, we image three zones of extremely high resistivity with average resistivities of 7000, 2500 and $10000 \Omega m$, from west to east, respectively. These resistive units may correspond to evaporitic diapirs within the surrounding Ioannina carbonate platform. Evaporitic diapirs are found throughout the region (Valaj, 2001), and the Delvinaki diapir, exposed $\sim 25 \mathrm{~km}$ to the NW was imaged by Karageorgi et al. (2002) as an extensive zone of high resistivity (2000-10000 $\Omega \mathrm{m}$ ). The shallow conductive zones to the west and east of the Ioannina platform are attributed to the Pindus Flysch within the Botzara Syncline and Zagoria Basin, respectively. The Ioannina SES station (PER) lies above the most resistive of the inferred evaporate bodies and it is surrounded by conductive bodies on a range of scales.

\section{Conclusions}

The analysis scheme followed in this paper is summarized in Fig. 12. Groom-Bailey decomposition of the 42 sites in the Ioannina dataset indicates the existence of a 2-D regional conductivity structure coupled with localized 3-D near-surface galvanic distortion. 31 sites were found to suffer from strong galvanic distortion. Mohr circle analysis likewise supports a 2-D regional conductivity structure, with highly anisotropic responses found for 35 sites. It furthermore determines a regional strike of $\mathrm{N} 35^{\circ} \mathrm{W}$, applicable within most of the central survey area. This last result is quite important, as the boundary of this region may mark the area where an electric signal from an embedded, current-emitting dipole source could be observed.

Two lines of evidence support the conclusion that the regional conductivity structure is 2-D. First, the dataset is largely characterized as 2-D based on consistency among the

\footnotetext{
${ }^{1}$ Bedrosian, P. and Balasis, G.: Magnetotelluric investigation of the Ioannina plateau, Tectonophysics, in preparation, 2005.
} 
(a)
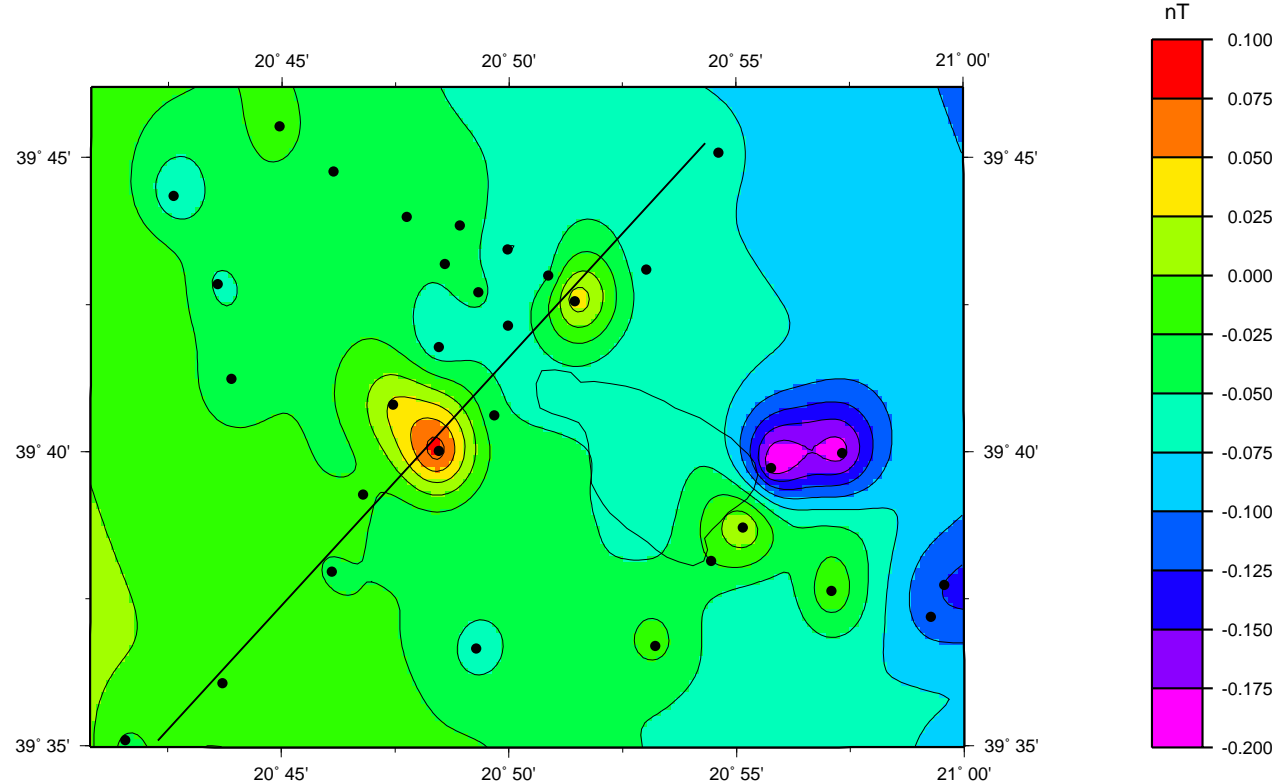

(b)

Predicted $\operatorname{Im}\left(\mathrm{H}_{\mathrm{z}}\right), \mathrm{T}=50 \mathrm{~s}, \theta^{*}=135^{\circ}$
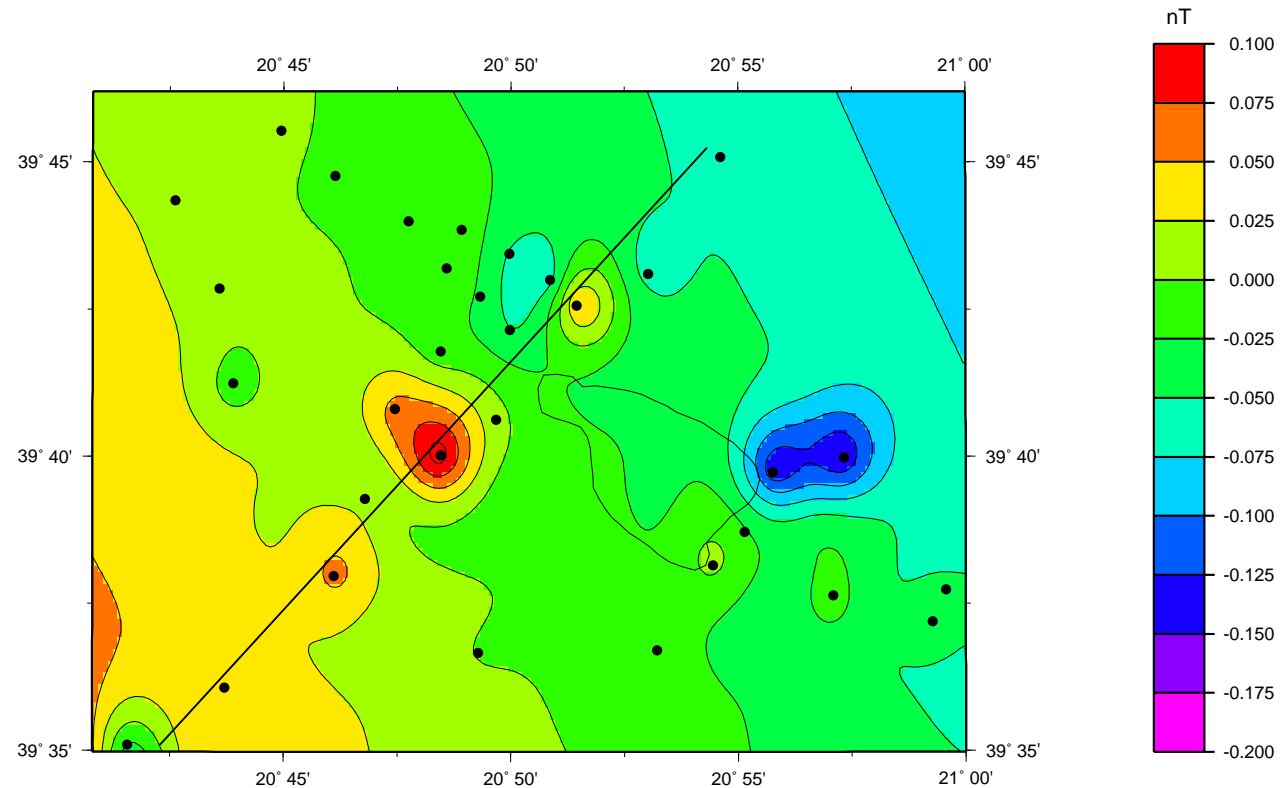

Fig. 9. Hypothetical event maps of $\Re H_{z}^{p}$ (a) and $\Im H_{z}^{p}$ (b) at $T=50 \mathrm{~s}$ for $\vartheta^{*}=135^{\circ}$. The line indicates a 2-D inversion profile.

majority of sites. Second, in Mohr circle analysis no a priori assumption has been made regarding the dimensionality of the structure: circles were simply constructed by rotation of the elements of the MT impedance tensor. Then, the classification for each site is made by comparison of the resulting circles with the forms described by Lilley (1993) for different dimensionality cases. Finally, we would also like to note the difficulties/limitations of doing a 3-D interpretation (e.g. site layout and computational difficulties). Most importantly, as pointed out by Ledo et al. (2002) a careful 2-D interpretation of certain types of 3-D data is reasonable (e.g. a 3-D conducting body of limited extent striking at $45^{\circ}$ to a regional 2-D dipping structure). In fact, although the data were 3-D the first-order structures were obtained by 2-D interpretation techniques: the 2-D inversion models resembled the main characteristics of the true 3-D model.

Induction arrows and Hypothetical Event Analysis both reveal a consistent, regional 2-D inductive response at long periods $(T \geq 140 \mathrm{~s})$ and a corresponding strike direction of $\mathrm{N} 45^{\circ} \mathrm{W}$, in agreement with the trend of the nearby coastline 

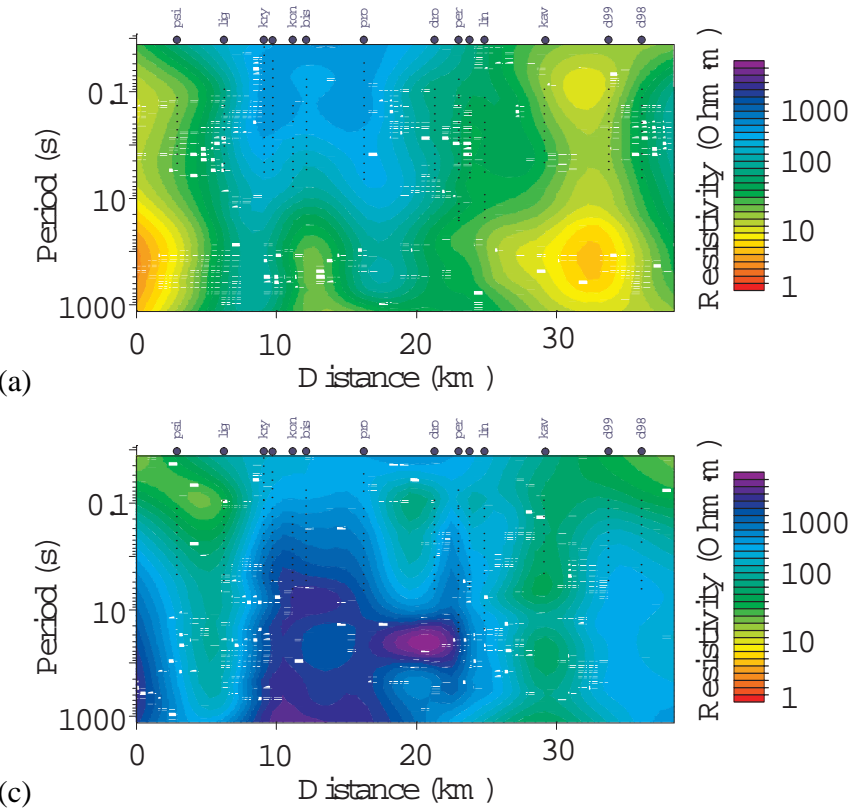

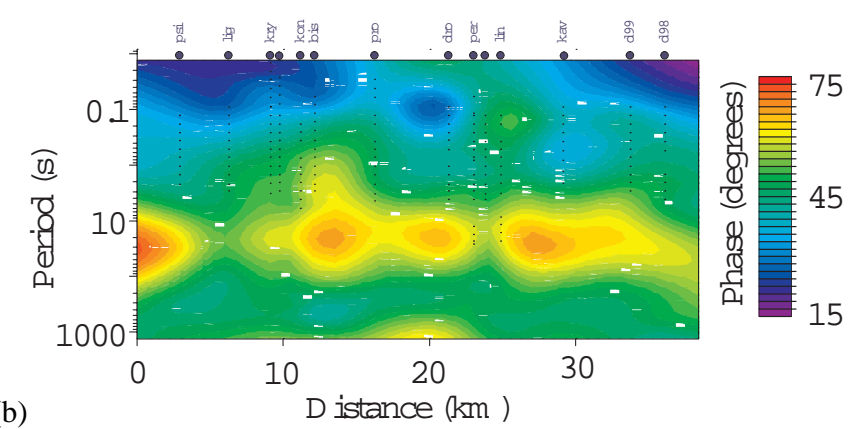

(b)

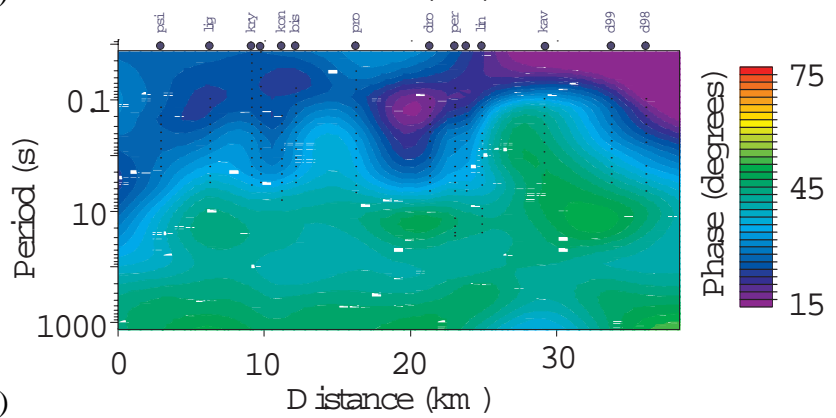

Fig. 10. Pseudosections of the TE (a)-(b) and TM mode (c)-(d) apparent resistivities and phases along a $35 \mathrm{~km}$ profile crossing the Ioannina area and consisting of 14 sites.

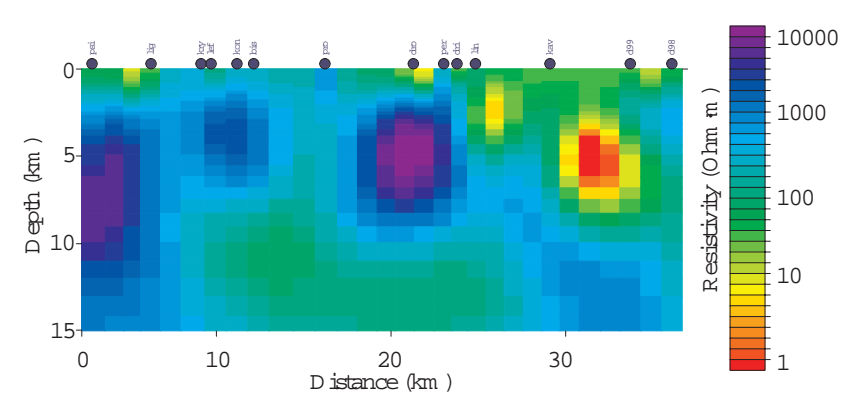

Fig. 11. 2-D inversion resistivity model of the Ioannina profile.

and the geological setting of Ioannina region. At intermediate periods $(50 \mathrm{~s} \leq T<140 \mathrm{~s})$ HEA recovers a strike angle of $\mathrm{N} 45^{\circ} \mathrm{W}$, in addition to revealing a number of local magnetic distorters. Ioannina SES station (PER) lies above a strong gradient of the magnetic field.

In this region, the coastline is sub-parallel to the major structural trends (including the Pindus chain) and the uniform and anti-parallel induction arrows likely reflect a superposition of these large-scale structures and the coastline.

The resistivity model inferred from 2-D inversions of a subset of the initial data reveals that Ioannina SES station PER is located above the most resistive $(\simeq 10000 \Omega m)$ of the three high resistivity units within the Ioannina platform. Additionally, conductive bodies were imaged surrounding the station. It is plausible that these conductors may be connected to a regional crustal conductor, as may be associated with mapped faults to the west and east of the survey area.

The abovementioned findings suggest that the regional and local conductivity structure under Ioannina station (PER) is suitable for collecting SES (see also Introduction): when a remote source is operating, the electric field amplitudes may be appreciably stronger near this location than at neighboring sites. The imaged conductivity structure is in accordance with the SES sensitivity of the Ioannina station that was previously found (Varotsos and Lazaridou, 1991; Varotsos et al., 1993) and consistent with the model suggested by Varotsos and Alexopoulos (1986).

We would also like to compare the findings from Ioannina case study with the results from another SES experiment and MT survey around a station in Zante island, within the Ionian Sea, western Greece. SES have been recorded simultaneously at Ioannina (PER) and Zante station. However, the amplitude of the SES recorded at the Ioannina station is significantly larger, although the distance from the focal area of several large earthquakes, that occurred during the period of the experiment, was smaller to Zante than Ioannina station (Kopanas et al., 1994). The conductivity structure surrounding the Zante station was found to be 2-D local/1-D regional with a very conductive regional background (Eftaxias et al., 2000) in contrast to the geoelectrical structure around Ioannina SES station (PER).

Acknowledgements. G. Balasis acknowledges support from the Greek State Scholarship Foundation (IKY) and DFG Priority Program SPP 1097. P. A. Bedrosian acknowledges support from the Alexander von Humboldt Foundation.

Edited by: P. F. Biagi

Reviewed by: A. Siniscalchi and A. Tzanis 


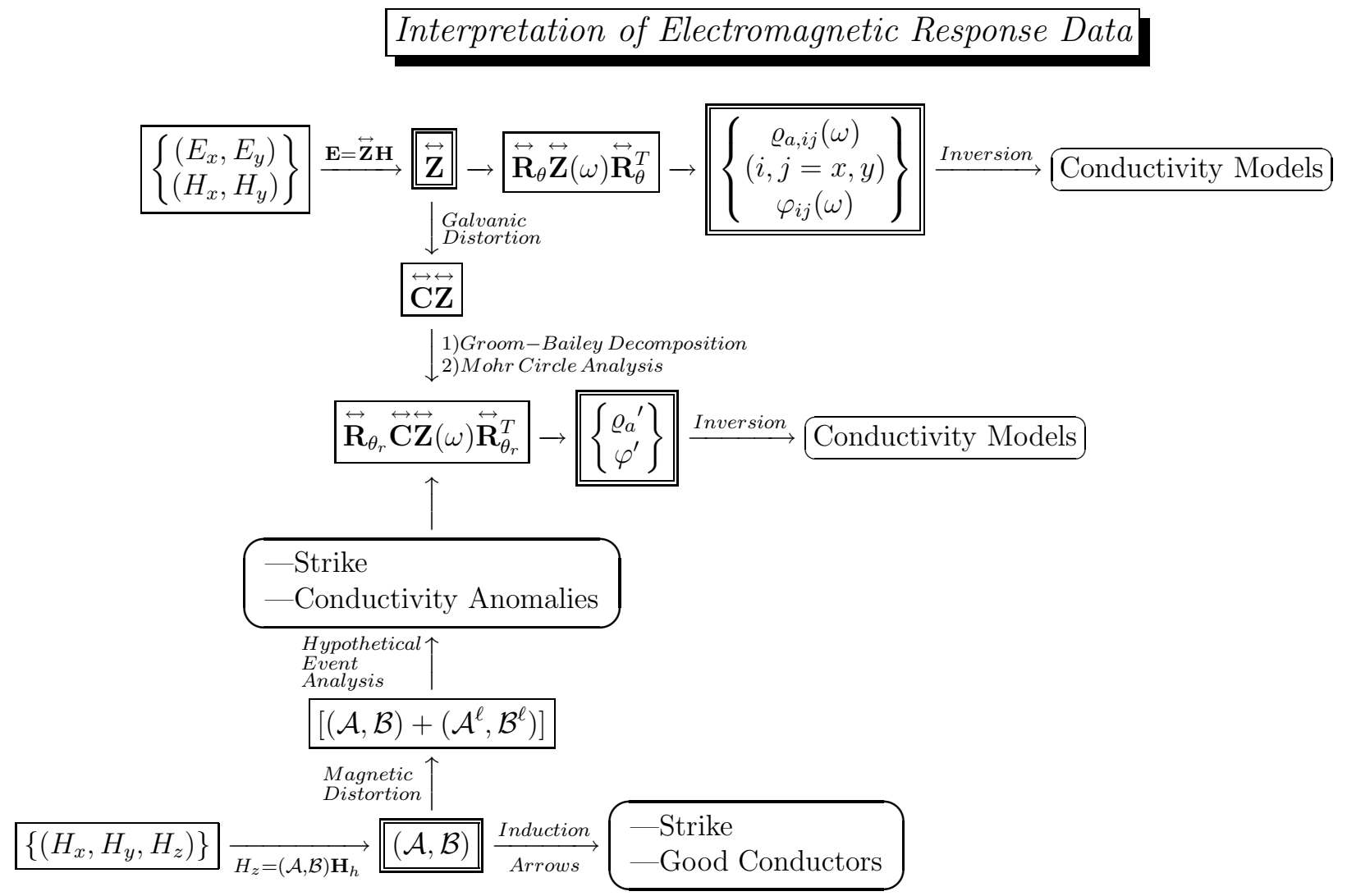

Fig. 12. Block diagram of the methodology utilized for the galvanic and magnetic distortion analysis.

\section{References}

Bahr, K.: Interpretation of the magnetotelluric impedance tensor: regional induction and local telluric distortion, Geophysics, 62, 119-127, 1988.

Bailey, R. C., Edwards, R. N., Garland, G. D., Kurtz, R., and Pitcher, D.: Electrical conductivity studies over a tectonical active area in Eastern Canada, J. Geomag. Geoelectr., 26, 125-146, 1974.

Balasis, G.: Modeling the Electric Properties of a Solid Section by Decomposition of the Electromagnetic Wave Impedance Tensor, PhD thesis, University of Athens, 2001.

Balasis, G., Bogris, N., and Eftaxias, K.: Magnetovariational and Magnetotelluric study of Ioannina region sensitive to Seismic Electric Signals (SES), II, J. Atmos. Electricity, 22, 139-164, 2002.

Banks, R. J., Livelybrooks, D., Jones, P., and Longstaff, R.: Causes of high crustal conductivity beneath the Iapetus suture zone in Great Britain, Geophys. J. Int., 124, 433-455, 1996.

Bedrosian, P. A., Unsworth, M. J., Egbert, G. D., and Thurber, C. H.: Geophysical images of the creeping San Andreas Fault: implications for the role of crustal fluids in the earthquake process, Tectonophysics, 385, 137-158, 2004.

Chave, A. D. and Smith, J. T.: On electric and magnetic galvanic distortion tensor decompositions, J. Geophys. Res., 99, 46694682, 1994.

Eftaxias, K., Kopanas, J., Bogris, N., Kapiris, K., Antonopoulos, G., and Varotsos, P.: Detection of electromagnetic earthquake precursory signals in Greece, Proc. Japan Acad., 76(B), 45-50, 2000.
Eftaxias, K., Rokityansky, I., Bogris, N., Balasis, G., and Varotsos, P.: Magnetovariational and Magnetotelluric study of Ioannina region sensitive to Seismic Electric Signals (SES), I, J. Atmos. Electricity, 22, 113-137, 2002.

Groom, R. W. and Bailey, C. R.: Decomposition of magnetotelluric impedance tensors in the presence of local three-dimensional galvanic distortion, J. Geophys. Res., 94, 1913-1925, 1989.

Groom, R. W. and Bailey, C. R.: Analytic investigation of the effects of near surface three-dimensional galvanic scatterers on MT tensor decomposition, Geophysics, 56, 496-518, 1991.

Gurk, M.: Magnetic Distortion of GDS transfer functions: An example from the Penninic Alps of Eastern Switzerland revealing a crustal conductor, Earth Planets and Space, 51, 1023-1034, 1999.

Hadjicontis, V. and Mavromatou, C.: Laboratory investigation of electric signals preceding earthquakes, in: The critical review of VAN: Earthquake Prediction from Seismic Electric Signals, edited by: Sir Lighthill, J., World Scientific Publishing Co., Singapore, 105-117, 1996.

Ingham, M., Whaler, K., and McKnight, D.: Magnetotelluric sounding of the Hikurangi Margin, New Zealand, Geophys. J. Int., 144, 343-355, 2001.

Jones, A. G.: The problem of current channeling: a critical review, Geophys. Surveys, 6, 79-122, 1983.

Jones, A. G.: Static shift of magnetotelluric data and its removal in a sedimentary environment, Geophysics, 53, 967-978, 1988.

Kagan, Y. Y. and Jackson, D. D.: Statistical tests of VAN earthquake predictions: comments and reflections, Geophys. Res. Lett., 23, 1433-1436, doi:10.1029/95GL03786, 1996. 
Karageorgi, I., Watts, M. D., and Savvaidis, A.: Integration and correlation of geophysical data in NW Greece, EAGE 64th Conference and Exhibition, Florence, 2002.

Kopanas, J., Antonopoulos, G., Makris, J., Eftaxias, K., and Hadjicontis, V.: Detection of the SES vertical component, in: Electromagnetic phenomena related to earthquake prediction, edited by: Hayakawa, M. and Fujinawa, Y., Terra Scientific Publishing Company, Tokyo, 25-36, 1994.

Lazarus, D.: Note on a possible origin of seismic electric signals, Tectonophysics, 224, 265-267, 1993.

Ledo, J., Queralt, P., Marti, A., and Jones, A. G.: Two-dimensional interpretation of three-dimensional magnetotelluric data: an example of limitations and resolution, Geophys. J. Int., 150, 1, 127139, 2002.

Lilley, F. E. M.: Diagrams for magnetotelluric data, Geophysics, 41, 766-770, 1976.

Lilley, F. E. M.: Magnetotelluric analysis using Mohr circles, Geophysics, 58, 1498-1506, 1993.

Lilley, F. E. M.: Magnetotelluric tensor decomposition: Part I, Theory for a basic procedure, Geophysics, 63, 1885-1897, 1998a.

Lilley, F. E. M.: Magnetotelluric tensor decomposition: Part II, Examples of a basic procedure, Geophysics, 63, 1898-1907, 1998b.

Makris, J., Bogris, N., and Eftaxias, K.: A new approach in the determination of characteristic directions of the geoelectric structure using Mohr circles, Earth, Planets and Space, 51, 1059$1065,1999$.

Park, S. K.: Distortion of magnetotelluric sounding curves by threedimensional structures, Geophysics, 50, 785-797, 1985.

Pham, V. N., Boyer, D., Chouliaras, G., Le Mouël, J. L., Rossignol, J. C., and Stavrakakis, G. N.: Characteristics of electromagnetic noise in the Ioannina region (Greece); a possible origin for so called Seismic Electric Signal (SES), Geophys. Res. Lett., 25, 2229-2232, doi:10.1029/98GL01593, 1998.

Ramsay, J. G. and Huber, M. I.: Modern Structural Geology, Academic Press, pp. 700, 1987.

Ritter, O., Weckmann, U., Vietor, T., and Haak, V.: A magnetotelluric study of the Damara Belt in Namibia 1. Regional scale conductivity anomalies, Phys. Earth Planet. Inter., 138, 71-90, 2003.

Ritter, O., Hoffman-Rothe, A., Bedrosian, P. A., Weckmann, U., and Haak, V.: Electrical conductivity images of active and fossil fault zones, Microstructural Evolution and Physical Properties in High-Strain Zones, Geological Society of London Special Publication, 245, 165-186, 2005.

Ritter, P.: Separation of Local and Regional Information in Geomagnetic Response Functions using Hypothetical Event Analysis, $\mathrm{PhD}$ thesis, University of Edinburgh, 1996.

Ritter, P. and Banks, R. J.: Separation of local and regional information in distorted GDS response functions by hypothetical event analysis, Geophys. J. Int., 135, 923-942, 1998.

Rodi, W. and Mackie, R.: Non-linear conjugate gradients algorithm for 2-D magnetotelluric inversion, Geophysics, 66, 174 187, 2001.

Sarlis, N., Lazaridou, M., Kapiris, P., and Varotsos, P.: Numerical model of the selectivity effect and the $\Delta \mathrm{V} / \mathrm{L}$ criterion, Geophys. Res. Lett., 26, 3245-3248, 1999.
Schmucker, U.: Anomalies of geomagnetic variations in the southwestern United States, Bull. Scripps Inst. Ocean. Univ. Calif., 13, 1970.

Swift, C. M. J.: A magnetotelluric investigation of an electrical conductivity anomaly in the southwestern United States, $\mathrm{PhD}$ thesis, MIT, 1967.

Tzanis, A., Vallianatos, F., and Cruszow S.: Identification and discremination of transient electrical earthquake precursors: fact, fiction and some possibilities, Phys. Earth Planet. Interiors, 121, 223-248, 2000.

Tzanis, A. and Vallianatos, F.: A critical review of Electric Earthquake Precursors, Annali di Geofisica, 44, 2, 429-460, 2001.

Utada, H.: On the physical background of the VAN earthquake prediction method, Tectonophysics, 224, 153-160, 1993.

Uyeda, S.: Introduction to the VAN method of earthquake prediction, in: The Critical Review of VAN: Earthquake Prediction from Seismic Electric Signals, edited by: Sir Lighthill, J., World Scientific Publishing Co., Singapore, 3-28, 1996.

Varotsos, P. and Alexopoulos, K.: Stimulated current emission in the Earth and related geophysical aspects, in: Thermodynamics of Point Defects and their Relation with Bulk Properties, edited by: Amelinckx, S., Gevers, R., and Nihoul, J., 136-142, 403406, 410-412 and 417-420, North Holland, Amsterdam, 1986.

Varotsos, P. and Lazaridou, M.: Latest aspects of earthquake prediction in Greece based on Seismic Electric Signals, Tectonophysics, 188, 321-347, 1991.

Varotsos P., Alexopoulos, K., and Lazaridou, M.: Latest aspects of earthquake prediction in Greece based on seismic electric signals, II, Tectonophysics, 224, 1-37, 1993.

Varotsos, P., Lazaridou, M., Eftaxias, K., Antonopoulos, G., Makris, J., and Kopanas, J.: Short term earthquake prediction in Greece by Seismic Electric Signals, in: The Critical Review of VAN: Earthquake Prediction from Seismic Electric Signals, edited by: Sir Lighthill, J., World Scientific Publishing Co., Singapore, 29-76, 1996.

Varotsos, P., Sarlis, N., Lazaridou, M., and Kapiris, P.: Transmission of stress induced electric signals in dielectric media, J. Appl. Phys., 83, 60-70, 1998.

Velaj, T.: Evaporites in Albania and their impact on the thrusting processes, J. Balkan Geophys. Soc., 4, 9-18, 2001.

Vozoff, K.: The magnetotelluric method: Electromagnetic Methods, in: Applied Geophysics, edited by: Naibighian, M. N., Soc. of Expl. Geophys., 641-711, 1987.

Wiese, H.: Geomagnetische Tiefentellurik Teil II: die Streichrichtung der Untergrundstrukturen des elektrischen Widerstandes, erschlossen aus geomagnetischen Variationen, Geofisica pura e applicata, 52, 83-103, 1962.

Wei, W., Unsworth, M., Jones, A., Booker, J., Tan, H., Nelson, D., Chen, L., Li, S., Solon, K., Bedrosian, P., Jin, S., Deng, M., Ledo, J., Kay, D., and Roberts, B.: Detection of Widespread Fluids in the Tibetan Crust by Magnetotelluric Studies, Science, 292, 716718, 2001. 